\title{
An evaluation of analytical stream to groundwater exchange models: a comparison of gross exchanges based on different spatial flow distribution assumptions
}

\author{
M. Exner-Kittridge ${ }^{1}$, J. L. Salinas ${ }^{2}$, and M. Zessner ${ }^{3}$ \\ ${ }^{1}$ Centre for Water Resource Systems, Vienna University of Technology, Vienna, Austria \\ ${ }^{2}$ Institute of Hydraulic Engineering and Water Resources Management, Vienna University of Technology, Vienna, Austria \\ ${ }^{3}$ Institute of Water Quality, Resources and Waste Management, Vienna University of Technology, Vienna, Austria \\ Correspondence to: M. Exner-Kittridge (exner@waterresources.at)
}

Received: 28 June 2013 - Published in Hydrol. Earth Syst. Sci. Discuss.: 15 August 2013

Revised: 27 May 2014 - Accepted: 16 June 2014 - Published: 29 July 2014

\begin{abstract}
In this paper, a new method for estimating gross gains and losses between streams and groundwater is developed and evaluated against two existing approaches. These three stream to groundwater exchange (SGE) estimation methods are distinct in their assumptions on the spatial distribution of the inflowing and outflowing fluxes along the stream. The two existing methods assume that the fluxes are independent and in a specific sequence, while the third and newly derived method assumes that both fluxes occur simultaneously and uniformly throughout the stream. The analytic expressions in connection to the underlying assumptions are investigated through numerical stream simulations to evaluate the individual and mutual dynamics of the SGE estimation methods and to understand the causes for the differences in performance. The results show that the three methods produce significantly different results and that the mean absolute normalized error can have up to an order of magnitude difference between the methods. These differences between the SGE methods are entirely due to the assumptions of the SGE spatial dynamics of the methods, and the performance for a particular approach strongly decreases if its assumptions are not fulfilled. The assessment of the three methods through numerical simulations, representing a variety of SGE dynamics, shows that the method introduced, considering simultaneous stream gains and losses, presents overall the highest performance according to the simulations. As the existing methods provide the minimum and maximum realistic values of SGE within a stream reach, all three methods could
\end{abstract}

be used in conjunction for a full range of estimates. These SGE methods can also be used in conjunction with other endmember mixing models to acquire even more hydrologic information as both require the same type of input data.

\section{Introduction}

Groundwater and surface water interactions are an important process in hydrologic systems (Winter, 1998). These interactions within and around streams and rivers impact decisions on municipal water supply extractions, water pollution, riverine habitat, and many others. To make better decisions on these impacts, the stream to groundwater exchange (SGE) needs to be accurately quantified as stream losses and gains can account for a substantial proportion of the total flow and chemical load of a stream.

In general, when people consider how to estimate the flow losses or gains along a stream reach they would take a discharge measurement upstream, a discharge measurement downstream, subtract the two values, and the result would be considered the gain or loss of flow within the stream reach. Although this may be a relatively simple procedure to accomplish, the assumption that all flow within a stream reach must be either flowing into the stream or flowing out of the stream is in many cases an over simplification (Castro and Hornberger, 1991; Harvey and Bencala, 1993). Depending on local topography, geology, and the groundwater table, 
gains and losses into and out of the stream can be very dynamic even over short distances (Harvey and Bencala, 1993; Anderson et al., 2005; Payn et al., 2009). Consequently, what might have originally been estimated as a small gain to the stream from simply subtracting the upstream and downstream discharges might end up becoming a small loss out of the stream and a large gain into the stream. Without a proper method to estimate SGE, any attempt at estimating a water or nutrient mass balance would be difficult and laced with errors.

Harvey and Wagner (2000) and many other researchers use a more realistic conceptual model of flow pathways within a stream (Fig. 1). These major flow pathways include initial (or upstream) discharge ( $\left.Q_{\text {up }}\right)$, final (or downstream) discharge $\left(Q_{\text {down }}\right)$, stream gains from groundwater $\left(Q_{\text {gain }}\right)$, stream losses to groundwater ( $\left.Q_{\text {loss }}\right)$, and hyporheic flow ( $\left.Q_{\text {hyp }}\right)$. In this conceptual model, $Q_{\text {gain }}$ is considered to be pure groundwater entering the stream, and $Q_{\text {loss }}$ is stream water permanently leaving the stream. Hyporheic flow occurs when stream water temporarily leaves the stream into the surrounding groundwater (or more specifically the hyporheic zone), but returns again to the stream at some downstream location. During this temporary departure from the stream, additional biochemical reactions may occur that would not necessarily have occurred while in the stream itself. The mass is still retained in the stream and not lost (permanently) to the groundwater. Although the hyporheic flow pathways do occur and can be very important for stream ecosystems (e.g., the movement of oxygen into the hyporheic zone, nitrogen cycling, etc.), hyporheic flow will not be directly addressed in this study as the authors are most interested on fluxes that are permanently adding or removing mass over a significant length of stream. As hyporheic flows only temporarily leave the stream, the mass of the water is still retained over sufficient distances.

There are a number of methods to estimate gross stream gains and losses (Kalbus et al., 2006). The general categories are seepage meters, (heat or chemical) tracer tests, and hydraulic gradients derived from groundwater piezometers. Each has advantages and disadvantages. Seepage meters and groundwater piezometers are point measurements that can be accurate at a specific point, but in a heterogeneous system they may not represent the stream as a whole. However, chemical tracer tests are an aggregation of all fluxes along a stream reach, but do not represent any particular point along the stream. For this study, the focus is on the total aggregated flows over the stream reaches, so chemical tracer tests were found to be the most appropriate and inexpensive. Kalbus et al. (2006) and Scanlon et al. (2002) have a more thorough qualitative review of the different SGE methods.

Using chemical tracer tests for the source of data, the estimation of gross stream gains and losses is most frequently performed through numerical models like those similar to the OTIS (One-Dimensional Transport with Inflow and Storage) model developed by the USGS (United States Geological

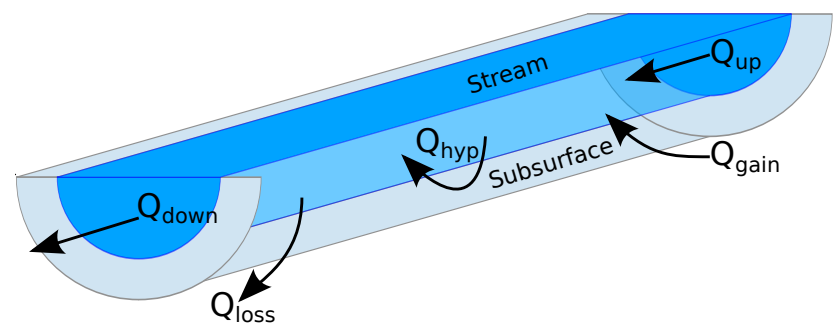

Figure 1. A conceptual overview of the major inflows and outflows within a stream reach. $Q_{\text {up }}$ is the upstream discharge in volume per time, $Q_{\text {down }}$ is the downstream discharge, $Q_{\text {gain }}$ is the groundwater entering the stream, $Q_{\text {loss }}$ is the stream water leaving the stream to the groundwater, and $Q_{\text {hyp }}$ is the hyporheic flow water that is temporarily leaving the stream into the hyporheic zone. (Reproduced after Harvey and Wagner, 2000.)

Survey) (Runkel, 1998). While able to estimate fluxes in steady-state conditions, these types of models are primarily designed for non-steady-state conditions and provide many output parameters in addition to the inflow and outflow fluxes and, as a consequence, require more input data than in steady-state conditions for estimating only SGE (e.g., stream cross-sectional area, flow advection, flow dispersion, etc.). Additionally, the OTIS type models would require the estimation of parameters, through a trial-and-error or an automated nonlinear least-squares (NLS) procedure, that are not directly measured. Under steady-state conditions, the data and parameter requirements for estimating only SGE are substantially lower requiring only discharge and tracer concentration measurements upstream and downstream. If a steady state is appropriate, then analytical methods are sufficient.

There are two existing analytical methods to estimate SGE under steady-state conditions ignoring hyporheic flow paths. These methods use simple mass balance equations to estimate both gains and losses within a stream reach and assume that the fluxes are independent and in a specific sequence. In this paper, a new analytical method has been developed using different assumptions on the spatial distribution of the inflowing and outflowing fluxes along the stream. The new spatial distribution assumptions are simultaneous and uniform inflows and outflows over the entire stream reach.

The goal of our study is to quantitatively evaluate the accuracy and sensitivity of the new method against the existing steady-state SGE tracer methods. This evaluation is performed through a combination of analytical comparisons and numerical stream simulations as described in the following sections. 


\section{Methods}

\subsection{Theoretical basis of the SGE tracer methods}

All tracer based methods designed to estimate SGE start with the conservation of mass equations under steady-state conditions for both the tracer and the water flux and assume complete mixing of the individual flows:

$Q_{\mathrm{up}} C_{\mathrm{up}}+Q_{\mathrm{gain}} C_{\mathrm{gain}}=Q_{\mathrm{down}} C_{\mathrm{down}}+Q_{\text {loss }} C_{\text {loss }}$,

$Q_{\text {up }}+Q_{\text {gain }}=Q_{\text {down }}+Q_{\text {loss }}$,

where $Q_{\text {down }}$ is the downstream discharge (in volume per unit time), $C_{\text {down }}$ is the downstream concentration (in mass per unit volume), $Q_{\text {up }}$ is the upstream discharge, $C_{\text {up }}$ is the upstream concentration, $Q_{\text {gain }}$ is the discharge from the groundwater to the stream, $C_{\text {gain }}$ is the concentration of $Q_{\text {gain }}, Q_{\text {loss }}$ is the discharge from the stream to the groundwater, and $C_{\text {loss }}$ is the concentration of $Q_{\text {loss }}$.

If we assume that $C_{\text {gain }}$ will be estimated later from the tracer test, then there are three unknown variables (i.e., $Q_{\text {gain }}$, $Q_{\text {loss }}$, and $C_{\text {loss }}$ ) and two equations. As we want to solve for $Q_{\text {gain }}$ and $Q_{\text {loss }}$, we must make some assumption about $C_{\text {loss }}$ to make the derivation solvable. The two existing SGE estimation methods mentioned in the introduction make specific assumptions on the distribution of gains and losses throughout the reach (see Fig. 2) to make appropriate assumptions about $C_{\text {loss. }}$ The first method, we call "Loss-Gain" assumes $C_{\text {loss }}=C_{\text {up }}$, while the second method, we call "Gain-Loss", assumes $C_{\text {loss }}=C_{\text {down }}$. In both variants, the methods assume that the mixing of $Q_{\text {gain }} C_{\text {gain }}$ and $Q_{\text {loss }} C_{\text {loss }}$ are mixed separately and in a sequence defined by the above assumptions. The Loss-Gain variant assumes that the mixing sequence begins with $Q_{\text {loss }}$ followed by $Q_{\text {gain }}$, while Gain-Loss is vice versa.

Combining Eqs. (1) and (2), the solution for $Q_{\text {loss }}$ for Loss-Gain is

$Q_{\text {loss }, \mathrm{LG}}=Q_{\mathrm{up}}-Q_{\mathrm{down}}\left(\frac{C_{\mathrm{down}}-C_{\text {gain }}}{C_{\mathrm{up}}-C_{\text {gain }}}\right)$.

Similarly, the equation for $Q_{\text {loss }}$ for Gain-Loss is

$Q_{\text {loss }, \mathrm{GL}}=Q_{\text {up }}\left(\frac{C_{\mathrm{up}}-C_{\text {gain }}}{C_{\mathrm{down}}-C_{\text {gain }}}\right)-Q_{\text {down }}$.

To get $Q_{\text {gain }}$ for both methods, we need to include Eq. (2) into Eqs. (3) and (4):

$Q_{\text {gain }, \mathrm{LG}}=Q_{\text {down }}\left(\frac{C_{\text {down }}-C_{\text {up }}}{C_{\text {gain }}-C_{\text {up }}}\right)$,
$Q_{\text {gain }, \mathrm{GL}}=Q_{\text {up }}\left(\frac{C_{\text {down }}-C_{\text {up }}}{C_{\text {gain }}-C_{\text {down }}}\right)$.

If we use an artificial tracer (e.g., bromide salt), we can safely assume $C_{\text {gain }} \approx 0$ and the resulting equations are as follows:

$Q_{\text {loss }, \mathrm{LG}}=Q_{\text {up }}-Q_{\text {down }} \frac{C_{\text {down }}}{C_{\text {up }}}$,

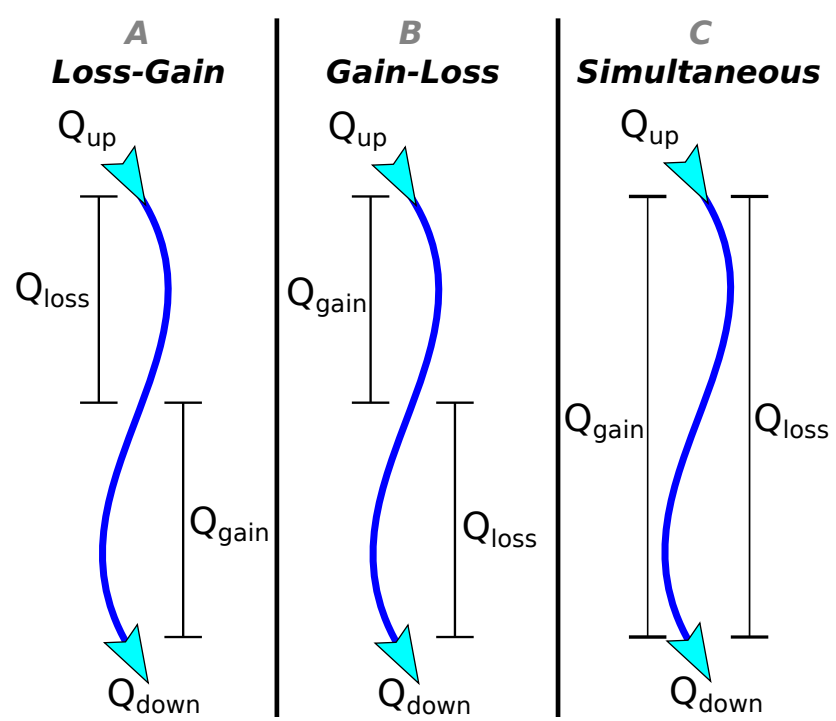

Figure 2. The conceptualizations of the three SGE methods (A) The LG ( $\mathrm{min}$ ) method assumes $Q_{\text {gain }}$ occurs in the first section followed by $Q_{\text {loss }}$ in the last section. (B) The GL (max) method assumes $Q_{\text {loss }}$ occurs in the first section followed by $Q_{\text {gain }}$ in the last section. Both the LG ( $\min$ ) and GL ( $\max$ ) methods assume that $Q_{\text {gain }}$ and $Q_{\text {loss }}$ occur in sequence and independently, although the lengths of the first and last sections are arbitrary and can be of any length that when summed together equal the total length. (C) The SIM method assumes that $Q_{\text {gain }}$ and $Q_{\text {loss }}$ are constant and occur simultaneously throughout the entire length of the stream reach.

$Q_{\text {loss }, \mathrm{GL}}=Q_{\text {up }} \frac{C_{\text {up }}}{C_{\text {down }}}-Q_{\text {down }}$,

and $Q_{\text {gain }}$ becomes

$Q_{\text {gain }, \mathrm{LG}}=Q_{\text {down }}\left(1-\frac{C_{\text {down }}}{C_{\text {up }}}\right)$,

$Q_{\text {gain, } \mathrm{GL}}=Q_{\text {up }}\left(\frac{C_{\text {up }}}{C_{\text {down }}}-1\right)$.

These methods can be applied conceptually along a stream length as illustrated in the A and B sections of Fig. 2. $Q_{\text {up }}$ is the upstream discharge and $Q_{\text {down }}$ represents the downstream discharge. Depending on the equation variant, $Q_{\text {gain }}$ is added or $Q_{\text {loss }}$ is removed from $Q_{\text {up }}$ at the beginning of the stream and $Q_{\text {loss }}$ is removed or $Q_{\text {gain }}$ is added at the end of the stream resulting in a downstream discharge of $Q_{\text {down }}$. As these methods make no assumptions about the exact location along the stream for $Q_{\text {gain }}$ and $Q_{\text {loss }}$, they can occur over any length of the stream as long as they occur in sequence and independently.

If a stream reach has some amount of $Q_{\text {gain }}$, then there is a certain significance to the Loss-Gain and Gain-Loss methods. The concentration of the conservative tracer starting at the location of $Q_{\text {up }}$ and ending at the location of $Q_{\text {down }}$ will have a tracer concentration that starts at the value of $C_{\text {up }}$, 
changing towards the concentration of $C_{\text {gain }}$ whenever $Q_{\text {gain }}$ enters the stream, and finally ending downstream at a value of $Q_{\text {down }}$ (which again is a value towards that of $C_{\text {gain }}$ ). As this occurs in every possible stream reach where $Q_{\text {gain }}>0$ and $C_{\text {gain }} \neq C_{\text {up }} \neq C_{\text {down }}, C_{\text {up }}$ and $C_{\text {down }}$ represent the endpoint concentrations along a stream reach. Subsequently, the Loss-Gain (with the $C_{\text {up }}$ assumption) and Gain-Loss (with the $C_{\text {down }}$ assumption) methods represent the minimum and maximum possible SGE values given the initial mass balance assumptions from Eqs. (1) and (2). This also means that any other SGE method must result in SGE values between the Loss-Gain and Gain-Loss methods. To provide the reader with an intuitive sense of both the underlying spatial distribution assumptions and the end point that these two methods represent, the Loss-Gain method will be called "LG (min)" and the Gain-Loss method will be called "GL (max)".

From studies that tested multiple stream reaches for SGE, almost every stream reach had both gains and losses regardless of the method and of the reach length (Anderson et al., 2005; Ruehl et al., 2006; Payn et al., 2009; Covino et al., 2011; Szeftel et al., 2011). Additionally, studies that have tried to identify the spatial distribution of groundwater inflows and outflows to and from the stream have found a wide variety of diffuse flow locations throughout the stream and were not limited to one or two flow locations every several hundred meters (Malard et al., 2002; Wondzell, 2005; Schmidt et al., 2006; Lowry et al., 2007; Slater et al., 2010). This indicates that even short stream reaches typically have many instances of gains and losses to and from the stream and that limiting the flux instances to one flux each regardless of the stream length may not be the most accurate assumption.

Following this rationale, this paper presents a new method based on a different assumption for the spatial distribution of SGE as compared to the GL $(\max )$ and LG $(\min )$ methods, namely that both $Q_{\text {gain }}$ and $Q_{\text {loss }}$ occur simultaneously and uniformly throughout the entire stream section. This new method is denoted as "SIM". Equations requiring the same input data as the GL $(\max )$ and LG (min) methods are derived in Sect. 2.2 and length is integrated into the mass balance equation (Fig. 3).

\subsection{Derivation of the method for simultaneous gains and losses}

In this section, the fundamental equations of mass balance for the tracer and water flows will be applied on a control volume represented in Fig. 3 under the assumption of simultaneous and uniform gains and losses throughout the stream reach and stationarity in time in order to obtain the expressions predicting $Q_{\text {gain }}$ and $Q_{\text {loss }}$ as functions of $Q_{\text {up }}, C_{\text {up }}, Q_{\text {down }}$, $C_{\text {down }}$ and $C_{\text {gain }}$. First, applying mass balance for discharge:

$Q(x)+q_{\text {gain }} \mathrm{d} x=Q(x)+\frac{\partial}{Q}(x) \partial x \mathrm{~d} x+q_{\text {loss }} \mathrm{d} x$,

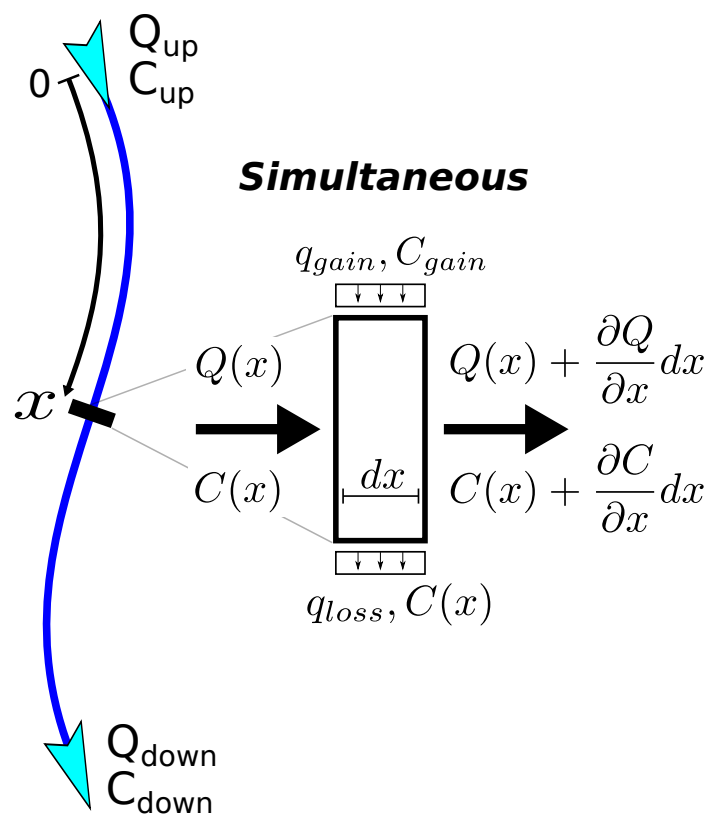

Figure 3. A conceptual representation of the analytical formulation of the SIM method.

where $x$ is distance along the stream, $Q(x)$ is the discharge at length $x, q_{\text {gain }}$ is the added discharge per unit length of stream, and $q_{\text {loss }}$ is the lost discharge per unit of length. Both $q_{\text {gain }}$ and $q_{\text {loss }}$ are assumed constant for a given stream reach. In the one-dimensional and stationary case, we can write $\frac{\partial Q(x)}{\partial x} \mathrm{~d} x=\mathrm{d} Q$. After rearranging and integrating from the beginning of the reach over an arbitrary length,

$\int_{Q_{\text {up }}}^{Q(x)} \mathrm{d} Q=\int_{0}^{x}\left(q_{\text {gain }}-q_{\text {loss }}\right) \mathrm{d} x$,

which becomes

$Q(x)=Q_{\text {up }}+\left(q_{\text {gain }}-q_{\text {loss }}\right) x$.

Then, applying mass balance for the tracer,

$$
\begin{aligned}
\dot{m}(x) & +C_{\text {gain }} q_{\text {gain }} \mathrm{d} x \\
& =\left(\dot{m}(x)+\frac{\partial \dot{m}(x)}{\partial x} \mathrm{~d} x\right)+C(x) q_{\text {loss }} \mathrm{d} x,
\end{aligned}
$$

where $\dot{m}(x)$ is the mass flow at length $x, C(x)$ is the concentration at length $x$, and $C_{\text {gain }}$ is the concentration of $q_{\text {gain }}$. $\dot{m}(x)$ is defined as $\dot{m}(x)=Q(x) \cdot C(x)$. The inflowing concentration $C_{\text {gain }}$ is assumed constant for a given stream reach. Again, in the one-dimensional and stationary case we can write $\frac{\partial \dot{m}(x)}{\partial x} \mathrm{~d} x=\mathrm{d} \dot{m}$. Taking into account the definition of $\dot{m}(x)$, we can write $d \dot{m}=\mathrm{d}(C \cdot Q)=Q \cdot \mathrm{d} C+C \cdot \mathrm{d} Q$. Rearranging the equation we get

$Q(x) \mathrm{d} C=C_{\text {gain }} q_{\text {gain }} \mathrm{d} x-C(x)\left(\mathrm{d} Q+q_{\text {loss }} \mathrm{d} x\right)$. 
Substituting Eqs. (12) and (13) for $Q(x)$ and $d Q$ respectively in Eq. (15), and rearranging, yields

$$
\mathrm{d} C=\frac{C_{\text {gain }} q_{\text {gain }} \mathrm{d} x-C(x)\left[\left(q_{\text {gain }}-q_{\text {loss }}\right) \mathrm{d} x+q_{\text {loss }} \mathrm{d} x\right]}{Q_{\text {up }}+\left(q_{\text {gain }}-q_{\text {loss }}\right) x} .
$$

Simplifying and integrating from the beginning of the reach over an arbitrary length $x$ yields

$\int_{C_{\text {up }}}^{C(x)} \frac{\mathrm{d} C}{C(x)-C_{\text {gain }}}=-q_{\text {gain }} \int_{0}^{x} \frac{\mathrm{d} x}{Q_{\text {up }}+\left(q_{\text {gain }}-q_{\text {loss }}\right) x}$

which becomes

$\ln \frac{C(x)-C_{\text {gain }}}{C_{\text {up }}-C_{\text {gain }}}=-\frac{q_{\text {gain }}}{q_{\text {gain }}-q_{\text {loss }}} \ln \frac{Q_{\text {up }}+\left(q_{\text {gain }}-q_{\text {loss }}\right) x}{Q_{\text {up }}}$.

Evaluating Eq. (13) for $x=L$, where $L$ represents the total length of the stream reach, yields

$q_{\text {gain }}-q_{\text {loss }}=\frac{Q_{\text {down }}-Q_{\text {up }}}{L}$.

Substituting Eq. (19) in Eq. (18) and evaluating for $x=L$ yields

$\ln \frac{C_{\text {down }}-C_{\text {gain }}}{C_{\text {up }}-C_{\text {gain }}}=-\frac{q_{\text {gain }}}{\frac{Q_{\text {down }}-Q_{\text {up }}}{L}} \ln \frac{Q_{\text {down }}}{Q_{\text {up }}}$.

Calling $Q_{\text {gain }}=q_{\text {gain }} \cdot L$ and rearranging yields

$Q_{\text {gain }, \mathrm{SIM}}=\left(Q_{\text {up }}-Q_{\text {down }}\right) \frac{\ln \left[\frac{C_{\text {down }}-C_{\text {gain }}}{C_{\text {up }}-C_{\text {gain }}}\right]}{\ln \left[\frac{Q_{\text {down }}}{Q_{\text {up }}}\right]}$.

If we substitute Eq. (2) for $Q_{\text {gain,SIM }}$ in Eq. (21), the solution for $Q_{\text {loss }}$ is

$Q_{\text {loss }, \mathrm{SIM}}=\left(Q_{\text {up }}-Q_{\text {down }}\right) \frac{\ln \left[\frac{Q_{\text {down }}\left(C_{\text {down }}-C_{\text {gain }}\right)}{Q_{\text {up }}\left(C_{\text {up }}-C_{\text {gain }}\right)}\right]}{\ln \left[\frac{Q_{\text {down }}}{Q_{\text {up }}}\right]}$,

where $Q_{\text {gain,SIM }}$ and $Q_{\text {loss,SIM }}$ are the SIM equations for the SGE into and out of the stream, respectively.

As with the previous methods, if we use an artificial tracer (e.g., bromide salt) we can safely assume $C_{\text {gain }} \approx 0$ and the resulting equations are as follows:

$Q_{\text {gain }, \text { SIM }}=\left(Q_{\text {up }}-Q_{\text {down }}\right) \frac{\ln \left[\frac{C_{\text {down }}}{C_{\text {up }}}\right]}{\ln \left[\frac{Q_{\text {down }}}{Q_{\text {up }}}\right]}$

and

$$
Q_{\text {loss }, \text { SIM }}=\left(Q_{\text {up }}-Q_{\text {down }}\right) \frac{\ln \left[\frac{Q_{\text {down }} C_{\text {down }}}{Q_{\text {up }} C_{\text {up }}}\right]}{\ln \left[\frac{Q_{\text {down }}}{Q_{\text {up }}}\right]} .
$$

Equations (21)-(24) are discontinuous when $Q_{\text {up }}=Q_{\text {down }}$. Fortunately, this is a removable discontinuity and can be solved by applying L'Hôpital's rule (Arfken and Weber, 2005). Applying L'Hôpital's rule to Eq. (21) and differentiating for $Q_{\text {up }}$ results in the following:

$Q_{\text {gain }, \mathrm{SIM}}=-Q_{\text {up }} \cdot \ln \left[\frac{C_{\text {down }}-C_{\text {gain }}}{C_{\text {up }}-C_{\text {gain }}}\right]$.

Equation (25) is the solution for the condition that $Q_{\text {up }}=Q_{\text {down }}$ and applies to both $Q_{\text {gain,SIM }}$ and $Q_{\text {loss,SIM }}$ as they will produce the same result in that situation. This is only a mathematical exception and should not be needed in practice as $Q_{\text {up }}$ and $Q_{\text {down }}$ should not truly be equal when measured in the natural environment due to the natural heterogeneity of streams and the inherent measurement error of the method to measure discharge.

Naturally occurring tracers (e.g., chloride salt) can also be applied to the SGE equations with additional information about $C_{\text {gain }}$. As long as a quasi-steady-state condition applies and that $Q_{\text {gain }}>0$, the only additional information to be collected would be the $C_{\text {up }}$ and $C_{\text {down }}$ prior to the injection of the tracer. For the derivation, we can use any one of the three SGE methods (six possible equations) and they all will produce the same final equation as the final equation is not reliant on spatial distribution assumptions. For a more thorough derivation starting from the initial mass balance equations, refer to Appendix A. For simplicity, we will use the $Q_{\text {gain,LG }}$ equation from Eq. (5). As the value of $Q_{\text {gain,LG }}$ will be the same before and after the tracer injection, we can make two versions of the $Q_{\text {gain,LG }}$ before and after the tracer injection with a different $C_{\text {up }}$ and $C_{\text {down }}$ prior to the injection of the tracer and post injection of the tracer.

$$
\begin{aligned}
Q_{\text {down }} & \left(\frac{C_{\text {down,prior }}-C_{\text {up,prior }}}{C_{\text {gain }}-C_{\text {up,prior }}}\right) \\
= & Q_{\text {down }}\left(\frac{C_{\text {down,post }}-C_{\text {up,post }}}{C_{\text {gain }}-C_{\text {up,post }}}\right)
\end{aligned}
$$

and with some rearrangement, we come to our final equation:

$C_{\mathrm{gain}}=\frac{C_{\mathrm{up}, \text { prior }} C_{\mathrm{down}, \text { post }}-C_{\mathrm{down}, \text { prior }} C_{\mathrm{up}, \text { post }}}{C_{\mathrm{up}, \text { prior }}-C_{\mathrm{up}, \text { post }}-C_{\mathrm{down}, \text { prior }}+C_{\mathrm{down}, \text { post }}}$,

where $C_{\text {up,prior }}$ is the upstream concentration prior to the tracer injection, $C_{\text {up,post }}$ is the upstream concentration from the tracer injection, $C_{\text {down,prior }}$ is the downstream concentration prior to the tracer injection, and $C_{\text {down,post }}$ is the downstream concentration from the tracer injection. The only main disclaimer to the application of this equation in the field is that the difference between $C_{\text {up,prior }}$ and $C_{\text {down,prior }}$ must be large enough to be statistically significant when estimated using available laboratory or field measurement techniques. The accuracy of the measurement techniques is a general problem for any chemical tracer test performed to estimate 
SGE. If the difference between the $Q_{\text {up }}$ and $Q_{\text {down }}$ is very small, much tracer may be needed to accurately measure a concentration difference between $C_{\text {up }}$ and $C_{\text {down }}$. This issue will become more important with larger rivers as the proportion of the $Q_{\text {gain }}$ and $Q_{\text {loss }}$ to the $Q_{\text {up }}$ is substantially reduced.

It would also be possible to estimate $C_{\text {gain }}$ from groundwater piezometers adjacent to the bank of the stream. As the intent of our study was to determine integrated values over a stream reach rather than point values, we preferred to use Eq. (27) as it is an integrated value of $C_{\text {gain }}$.

The application of tracer methods to measure SGE in the field is typically performed by two different techniques: constant injection and slug injection. These two techniques have been well researched in the scientific community and will not be evaluated in this study (Wagner and Harvey, 1997; Payn et al., 2008). Both techniques can be used with the above SGE methods and provide very similar results. As slug injections cause the $C_{\text {down }}$ to not be in a steady state, $C_{\text {down }}$ must be continuously measured and integrated over the measurable period of time. A more thorough explanation can be found in Payn et al. $(2008,2009)$ and Covino et al. (2011). For simplicity, we will assume constant injection with steady-state conditions.

\subsection{Evaluation methods}

\subsubsection{Analytics}

All three SGE methods were broken down analytically to better understand the dynamics of the equations of the methods. We wanted to know what caused the differences in the results of the three SGE methods and how these differences were related. The relative differences between the methods were accomplished by the ratio of one method's equation to another both analytically and illustratively.

\subsubsection{Numerical simulations}

Perfect measurements or estimates of SGE are impossible using any existing method. Arbitrarily comparing results of different methods using field collected data will only indicate that the different methods produce different results, and it will not indicate if one method is more accurate than another. Consequently, we thought that it would be appropriate to simulate artificial streams with known SGE for comparisons. With SGE perfectly known, we could effectively evaluate the accuracy of the different methods.

We simulated the lateral inflows and outflows per unit length throughout a stream using an autoregressive integrated moving average (ARIMA) model performed using the arima.sim package in the $\mathrm{R}$ statistical computing environment ( $\mathrm{R}$ Development Core Team, 2011). The routine generates a variety of artificial time series with both a randomness and memory component. To represent a small stream, the ARIMA model was designed to take a random discharge of between 1 and $5 \mathrm{~L} \mathrm{~s}^{-1}$ as input discharge and a random input tracer concentration of between 20 and $150 \mathrm{mg} \mathrm{L}^{-1}$ to represent practical tracer test concentrations.

In an attempt to create realistic simulations of the streams, we tuned the ARIMA model to have spatial flux dynamics based on studies using distributed temperature sensing (DTS) of groundwater inflows within streams (Lowry et al., 2007; Westhoff et al., 2007; Briggs et al., 2012; Mwakanyamale et al., 2012). The quantitative surrogate we used for the spatial flux dynamics was the average length that the fluxes would switch from inflow to outflow or vice versa within a stream reach. For example, if we simulate a stream with $1000 \mathrm{~m}$ total length and the fluxes in this stream oscillate between inflows and outflows 10 times then the average length per switch would be $100 \mathrm{~m}$. For our simulations, we used two different switch lengths of 100 and $200 \mathrm{~m}$ and total stream lengths of 1000 and $2000 \mathrm{~m}$. The switch lengths had a strong linear relationship with the correlation lengths and resulted in correlation lengths of 40 and $70 \mathrm{~m}$ for the switch lengths of 100 and $200 \mathrm{~m}$, respectively. Correlation length is commonly defined as the length at $1 / e$ on the autocorrelation distribution (Blöschl and Sivapalan, 1995).

We used stream lengths of 1000 and $2000 \mathrm{~m}$ in the simulations for two main reasons. First, the stream lengths of 1000 and $2000 \mathrm{~m}$ scale well with the switching lengths of 100 and $200 \mathrm{~m}$ and could easily be converted to nondimensional values if needed. Second, the lengths fit within practical tracer test lengths that have been performed in the past to determine stream to groundwater exchange, albeit towards the upper end (Covino et al., 2011). In practice, the appropriate stream lengths will be dependent on the discharge in the stream, the available mass of tracer, and the sensitivity and accuracy of the laboratory analytical methods.

The ARIMA model allowed us to create 5000 simulations of stream fluxes within a hypothetical stream. We ran four series of 5000 simulations. Series A had a $1000 \mathrm{~m}$ stream length and a $100 \mathrm{~m}$ average switch length, series B had a $1000 \mathrm{~m}$ and a $200 \mathrm{~m}$ average switch length, series $\mathrm{C}$ had a $2000 \mathrm{~m}$ and a $100 \mathrm{~m}$ average switch length, and series D had a $2000 \mathrm{~m}$ and a $200 \mathrm{~m}$ average switch length. The spatial discretization of the model was $1 \mathrm{~m}$ for all series and simulations. These four series of simulations were to test the effects of both length and intermittency on the stream flux methods. Without loss of generality, we defined $C_{\text {gain }}=0$ for the simulations, which would be equivalent to the use of an artificial tracer (e.g., bromide salt) for the tracer test.

We tested two distinct assumptions when deciding on the appropriate SGE ARIMA model. One assumption was that both $Q_{\text {gain }}$ and $Q_{\text {loss }}$ can occur simultaneously at one point. For example, if the groundwater table is sloped perpendicular to the stream then water would be flowing into one side of the bank, while water would be flowing out of the other side of the bank. In this assumption, we created two separate and independent vectors of $Q_{\text {gain }}$ and $Q_{\text {loss }}$ along the stream. 
The second assumption was that both $Q_{\text {gain }}$ and $Q_{\text {loss }}$ cannot occur simultaneously at one point. In this assumption, only one vector of SGE was created that could oscillate between $Q_{\text {gain }}$ and $Q_{\text {loss }}$. We decided to omit the option for simultaneity of $Q_{\text {gain }}$ and $Q_{\text {loss }}$ throughout the stream as this assumption coincided too closely with the assumption in the SIM method. To ensure a more rigorous evaluation against the SIM method, we decided to omit the ARIMA model assumption of simultaneity and only use the nonsimultaneity assumption for the simulations.

We attempted to simulate the stream with realistic dynamics of SGE, but we also tried to keep the model complexity as simple as possible. Although we did attempt to cover a wide range of SGE conditions when creating the many simulations, we undoubtedly did not cover all possible SGE conditions that could exist in nature. Realistically, the scientific community does not even know the full range of possibilities for natural SGE. We have also likely created simulations of SGE that do not exist in nature. Both issues are unavoidable when creating hydrologic simulations, particularly with the stochastic generation approach used in this paper. The hope is that the flux distributions of the simulations do closely represent reality for the purpose of our evaluation.

The statistical evaluation consisted of several methods and procedures. First, we took all of the simulated scenarios (5000 in our case) within an individual series and averaged the inflows and outflows for each simulation. This gave us an average inflow to the stream and outflow from the stream over the entire length of the stream for each scenario and served as our "true" values of the fluxes that the other SGE methods would be compared to. Next, we calculated the SGE of each scenario using the three SGE methods from the starting and end values of the scenarios. We did not include additional randomness in the input values for the SGE methods, which would equate to measurement error. This is due to the large variety of measurement devices and techniques that could be used in a tracer test, and each device and technique would have different measurement errors associated with them. Additionally, we calculated the net flux (we will call "Net") simply by subtracting $Q_{\text {up }}$ from $Q_{\text {down }}$. We considered the Net as the upper error benchmark for the evaluation as the estimation of Net requires less information and should therefore perform worse than the other three SGE methods that require more information.

Once the SGE was calculated for all of the methods to be evaluated, we used as a performance measure the absolute normalized error for method $m$ and for each simulation $i$, defined as

$\varepsilon_{i}^{\mathrm{m}}=\left|\frac{Q_{\mathrm{est}, i}^{\mathrm{m}}-Q_{\text {true }, i}}{Q_{\text {true }, i}}\right| i=1, \ldots, 5000$,

where $Q_{\mathrm{est}, i}^{\mathrm{m}}$ is the estimated gross gain or loss value from the SGE method $m$ and simulation $i$ and $Q_{\text {true }, i}$ is the average flux from the ARIMA model at simulation $i$. The results of $\varepsilon_{i}^{\mathrm{m}}$ are two vectors (one for gross gains and one for gross losses) for each of the four methods. Each vector contains 5000 elements, one for each scenario. To make an overall evaluation for each method, we simply took an average of all of the scenarios in each series for both vectors of gains and losses:

$\bar{\varepsilon}^{\mathrm{m}}=\frac{1}{n} \sum_{i=1}^{n} \varepsilon_{i}^{\mathrm{m}}$,

where $\bar{\varepsilon}^{\mathrm{m}}$ is the mean absolute normalized error (MANE) for each method $m$ (either flux leaving the stream or entering the stream) and $n$ is the total number of scenarios in each series (5000). This is a compound measure of relative bias and accuracy.

We also used the normalized root-mean-square error (NRMSE) as a supplement to the MANE:

$$
\mathrm{NRMSE}=\frac{\sqrt{\frac{1}{n} \sum_{i=1}^{n}\left(Q_{\mathrm{est}, i}^{\mathrm{m}}-Q_{\mathrm{true}, i}\right)^{2}}}{\frac{1}{n} \sum_{i=1}^{n} Q_{\mathrm{true}, i}} .
$$

The use of the NRMSE to supplement the MANE is to provide a higher weight to larger errors and scatter as compared to the MANE.

In addition to calculating the $\bar{\varepsilon}^{\mathrm{m}}$ for all of the SGE methods, we compared the $\varepsilon_{i}^{\mathrm{m}}$ within each of the SGE methods to determine how frequently one method outperformed another:

$r_{\mathrm{m} 1, \mathrm{~m} 2}=\frac{1}{n} \sum_{i=1}^{n} \begin{cases}1 & \text { if } \varepsilon_{i}^{\mathrm{m} 1}<\varepsilon_{i}^{\mathrm{m} 2} \\ 0 & \text { if } \varepsilon_{i}^{\mathrm{m} 1} \geq \varepsilon_{i}^{\mathrm{m} 2},\end{cases}$

where $r_{\mathrm{m} 1, \mathrm{~m} 2}$ is the frequency of $\mathrm{m} 1 \mathrm{SGE}$ method outperforming $\mathrm{m} 2 \mathrm{SGE}$ method.

Once $\varepsilon_{i}^{\mathrm{m}}$ and $\bar{\varepsilon}^{\mathrm{m}}$ were estimated, we wanted to determine the causes of the errors in the individual methods. This was accomplished through a correlation of $\varepsilon_{i}^{\mathrm{m}}$ to various combinations of the input parameters.

\section{Results}

\subsection{Analytics}

When there is 0 flux of either $Q_{\text {gain }}$ or $Q_{\text {loss }}$ all three equations produce the same results. For example, if $Q_{\text {loss }}=0$ then Eq. (2) becomes

$Q_{\text {down }}=Q_{\text {up }}+Q_{\text {gain }}$.

As $Q_{\text {down }}$ and $Q_{\text {up }}$ are previously known, there is only one solution for $Q_{\text {gain }}$ regardless of the other equations. Similarly, as the ratio of $Q_{\text {gain }}$ to $Q_{\text {loss }}$ grows to infinity or to 0 , the results for the three equations will converge. 

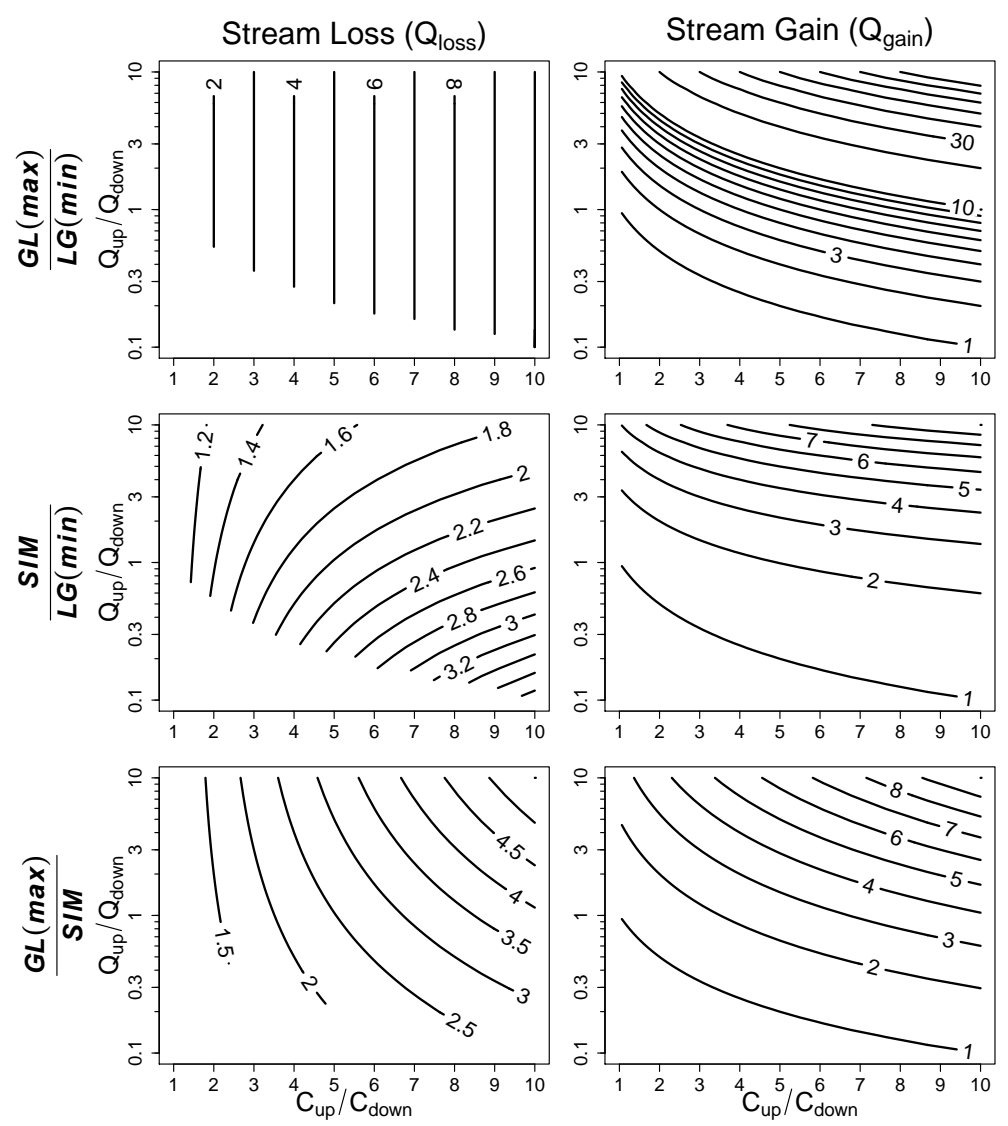

Figure 4. Relative comparisons between the different methods due to changes in the input ratios. The rows are the ratios of two of the SGE methods and the columns are the results for $Q_{\text {loss }}$ and $Q_{\text {gain }}$. In the two graphs in the middle panels, for example, if the ratio of the input parameters $C_{\text {up }}$ and $C_{\text {down }}$ is 5 and the ratio of the input parameters $Q_{\text {up }}$ and $Q_{\text {down }}$ is 1 then the SIM method will result in $Q_{\text {loss }}$ and $Q_{\text {gain }}$ being approximately 2 times larger than the $\mathrm{LG}(\mathrm{min})$ method. The $y$ axes of $\frac{Q_{\text {up }}}{Q_{\text {down }}}$ is on a logarithmic scale to ensure equal space weighting on the plot for $Q_{\text {up }}$ and $Q_{\text {down }}$. The $x$ axes are plotted from 1 to 10 as $C_{\text {up }} \geq C_{\text {down }}$.

Although somewhat obvious, if all of the assumptions are met for any of the SGE methods then the method will perfectly reproduce reality. For example, if there is only inflow to the stream from 1-100 $\mathrm{m}$ followed by only flow out of the stream from $101-1000 \mathrm{~m}$ then the GL ( $\max$ ) equation will estimate both fluxes perfectly.

If $Q_{\text {gain }}>0$ and if $C_{\text {gain }}<C_{\text {up }}$ then $C_{\text {down }}<C_{\text {up. Simi- }}$. larly, if $C_{\text {gain }}>C_{\text {up }}$ then $C_{\text {down }}>C_{\text {up }}$. This indicates that $C_{\text {up }}$ and $C_{\text {down }}$ are the concentration end points within the stream reach. As formulated in Eqs. (7)-(10), the LG (min) and GL ( $\max$ ) equations are divided by the end-point concentrations of the stream and will therefore represent the minimum and maximum values of fluxes within a stream reach. The LG (min) equations will always produce the minimum flux values, while the GL $(\max )$ equations will always produce the maximum flux values. Consequently, as LG(min) and GL (max) have the minimum and maximum flux values, the flux values for the SIM equations must be somewhere in between the two.
The GL (max) and LG (min) methods are very similar, and subsequently can be compared quite easily. Dividing the inflow and outflow equations for the two methods can show the rate of increase of one method over the other:

$\frac{Q_{\text {loss }, \mathrm{GL}}}{Q_{\text {loss }, \mathrm{LG}}}=\frac{C_{\mathrm{up}}}{C_{\mathrm{down}}}$

and

$\frac{Q_{\text {gain, } \mathrm{GL}}}{Q_{\text {gain }, \mathrm{LG}}}=\frac{Q_{\mathrm{up}} C_{\mathrm{up}}}{Q_{\text {down }} C_{\mathrm{down}}}$.

For both $Q_{\text {loss }}$ and $Q_{\text {gain }}$, GL (max) grows from LG (min) at a rate proportional to the concentration ratio, and additionally $Q_{\text {gain }}$ grows with load ratio. As $Q_{\text {loss }}$ and $Q_{\text {gain }}$ increase in a stream reach, $Q_{\text {down }}$ will change and $C_{\text {down }}$ will decrease. In the case of a lower $C_{\text {down }}$ caused by higher SGE, the ratio between the results of GL (max) and LG (min) grows larger (Fig. 4).

Unfortunately, the SIM method does not simplify nearly as well as the others due to the nonlinearity of the SIM equations. For a better visual comparison, the three methods were 

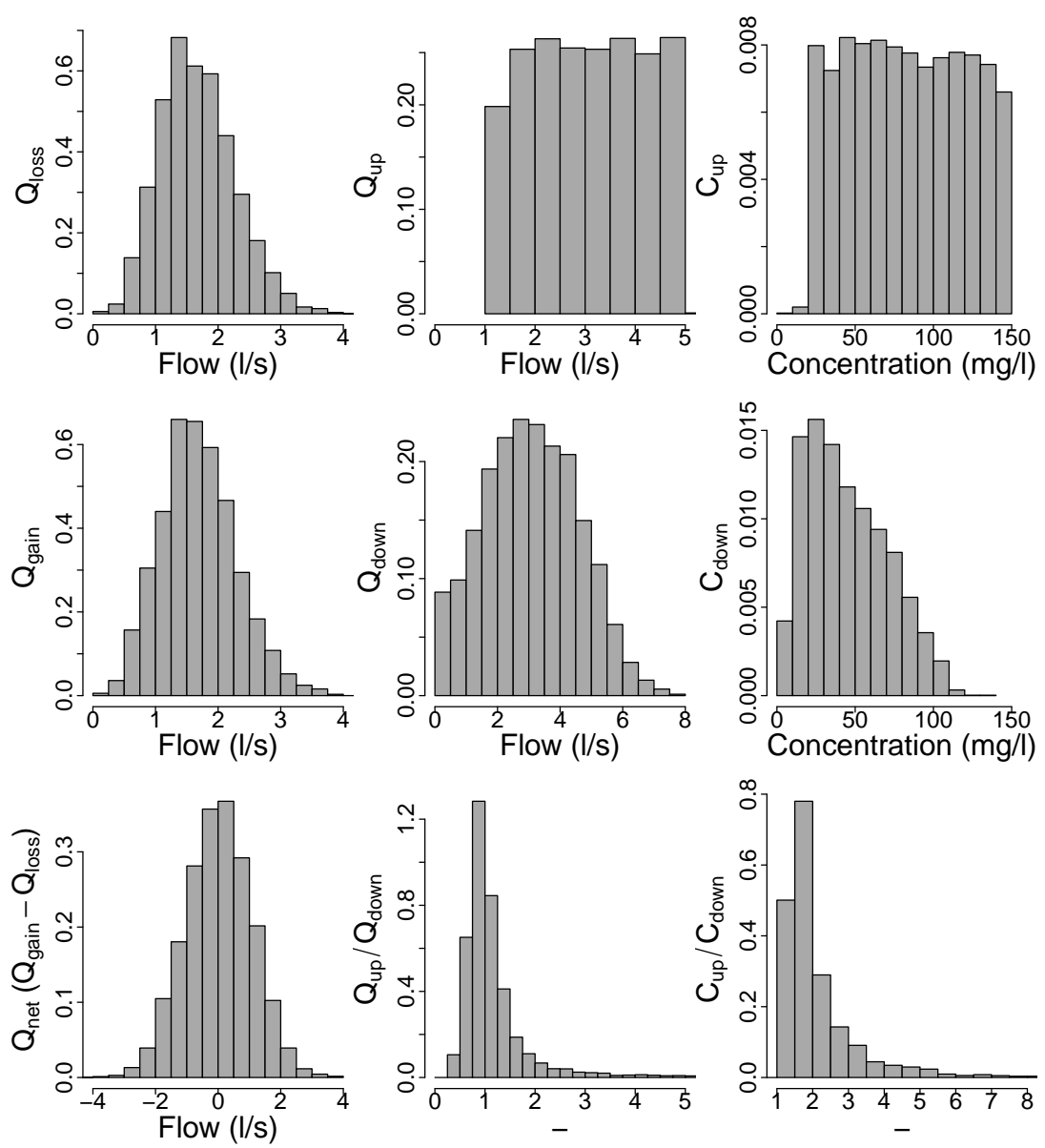

Figure 5. The major input and output parameter density distributions of the ARIMA numerical model for series A (1000 m with $100 \mathrm{~m}$ average switch length).

plotted together with axes of concentration and discharge ratios (Fig. 4). As shown analytically in Eqs. (33) and (34), the ratio of GL ( $\max$ ) to LG ( $\mathrm{min}$ ) is insensitive to discharge for $Q_{\text {loss }}$ and sensitive to both discharge and concentration for $Q_{\text {gain }}$. The ratios of SIM to the other methods illustrate the nonlinearity of the method. The methods' ratios for $Q_{\text {gain }}$ show a surprising similarity in the distribution of the contours even though the magnitudes are different.

\subsection{Numerical simulations}

Figure 5 presents the major input and output parameter density distributions created by the ARIMA simulations for the inflow and outflow profiles. The parameter distributions for $Q_{\text {loss }}, Q_{\text {gain }}$, and $Q_{\text {net }}$ closely follow a normal distribution. As defined in the model, $Q_{\text {up }}$ and $C_{\text {up }}$ are equally distributed between $1-5 \mathrm{~L} \mathrm{~s}^{-1}$ and $20-50 \mathrm{mg} \mathrm{L}^{-1}$, respectively.

The results of the numerical simulations are presented in Tables 1, 2, and 3. Plots of the estimated gains and losses to the actual gains and losses for each of the methods for series A are illustrated in Fig. 6. The plots for the other scenarios have similar patterns only with a greater or lesser degree of spread. The numerical simulations indicate that the SIM SGE method is on average the best performer when compared to the other two SGE methods, with a 1:1 slope to the true value, the lowest $\bar{\varepsilon}^{\mathrm{m}}$ and the NRMSE in every series, and the highest $r_{\mathrm{m} 1, \mathrm{~m} 2}$ in nearly every series. However, the LG (min) method has a slightly higher $r_{\mathrm{m} 1, \mathrm{~m} 2}$ to Net as compared to SIM. The LG (min) method also performed very well as compared to the SIM method according to the NRMSE. The LG (min) method had effectively the same error as SIM in series B and is very close in series D, both of which have the longer switch lengths. Interestingly, simply using the net discharge between upstream and downstream (Net) results in lower error values for $\bar{\varepsilon}^{\mathrm{m}}$ as compared to GL $(\max )$ in both $2000 \mathrm{~m}$ series, and GL $(\max )$ performed poorer than Net in all series according to the NRMSE. This is attributed to the fact that Net by definition cannot have an error of 1 or greater. Similarly, LG (min) also cannot have errors 1 or greater and must have errors less than those of Net. If 0 is used for all the values of $Q_{\text {gain }}$ and $Q_{\text {loss }}$ in the error assessment of $\bar{\varepsilon}^{\mathrm{m}}$, then $\bar{\varepsilon}^{\mathrm{m}}$ would be exactly 1 . GL $(\max )$ and SIM can have errors greater than 1 as they can have values larger than the true 

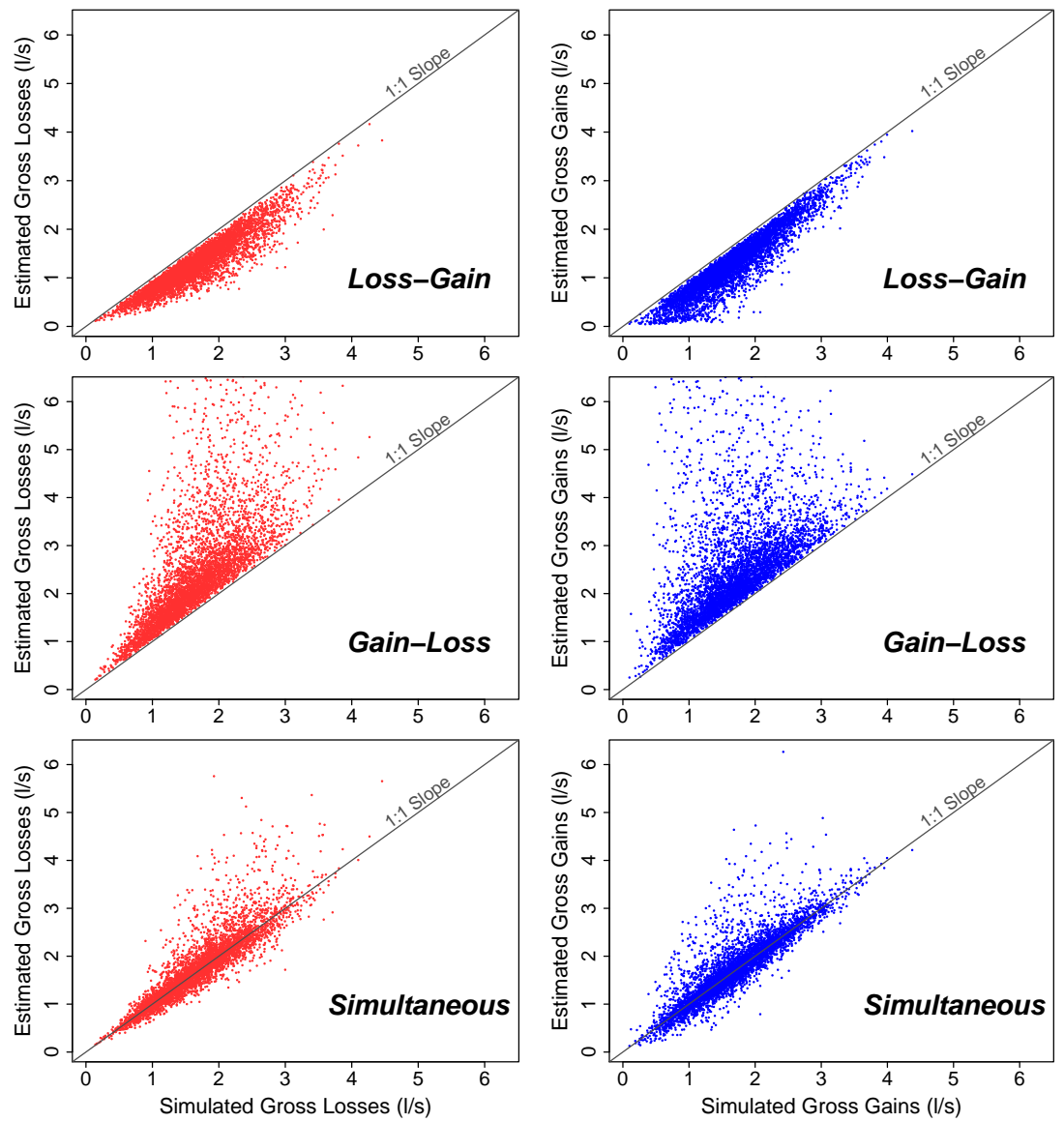

Figure 6. A plot of simulated inflow and outflow flux values by the estimated values from the three SGE methods using the $Q_{\text {up }}, Q_{\text {down }}$, $C_{\text {up }}$, and $C_{\text {down }}$ from series A simulations (1000 $\mathrm{m}$ with $100 \mathrm{~m}$ average switch length).

value, which is clearly exemplified by the GL (max) equation's high $\bar{\varepsilon}^{\mathrm{m}}$ and the NRMSE in some series.

Figures 7 and 8 show the six simulations with the smallest $\varepsilon_{i}^{\mathrm{m}}$ for both LG (min) and GL (max). Not surprisingly, they performed best when the assumptions of the individual methods were met. Figure 9 shows the six simulations with the smallest $\varepsilon_{i}^{\mathrm{m}}$ for SIM. No obvious conclusion can be drawn from the simulations other than an evenly random spread between $Q_{\text {gain }}$ and $Q_{\text {loss }}$ with no clear spatial trend unlike the other methods.

The ratios of $C_{\text {up }}$ to $C_{\text {down }}$ and $Q_{\text {up }} C_{\text {up }}$ to $Q_{\text {down }} C_{\text {down }}$ show a strong correlation to the $\varepsilon_{i}^{\mathrm{m}}$ of the SGE methods (Fig. 10). They are the same ratios that were found during the analytical evaluation described by Eqs. (33) and (34). Both LG ( $\min$ ) and GL ( $\max$ ) have stronger correlations than SIM. SIM appears to have an error trend towards lower values rather than the full range of the correlation.

LG (min) and GL (max) also have a strong correlation to the midpoint concentrations and loads. GL $(\max )$ had a strong correlation to the ratios of $C_{\text {mid }}$ (the midpoint of the concentration profile of the stream) to $C_{\text {down }}$ and $Q_{\text {up }} C_{\text {up }}$ to $Q_{\text {mid }} C_{\text {mid }}$ (the midpoint of the load profile of the stream).
$\mathrm{LG}$ (min) had a very strong correlation to the ratios of $C_{\mathrm{mid}}$ to $C_{\text {up }}$ and $Q_{\text {down }} C_{\text {down }}$ to $Q_{\text {mid }} C_{\text {mid }}$.

\section{Discussion}

\subsection{Evaluation of stream to groundwater exchange methods}

As described in earlier sections and shown by Fig. 6, the LG (min) and GL ( $\max )$ methods represent the minimum and maximum realistic SGE values and consequently will always produce SGE values below or above the true SGE values unless the individual spatial flux assumptions are perfectly met. This does not mean, however, that the SGE estimates from LG (min) and GL (max) will be equidistant from the true SGE value as shown in Fig. 6 and Tables 1 and 2.

LG (min) performed consistently better than GL (max) through all of the numerical simulation assessment measures (i.e., $\bar{\varepsilon}^{\mathrm{m}}$, the NRMSE, and $r_{\mathrm{m} 1, \mathrm{~m} 2}$ ). As described in the previous sections, the GL (max) equations can create results that can be many times larger than the other methods and consequently can be many times larger than the true value from the 


\section{Loss-Gain Series B}
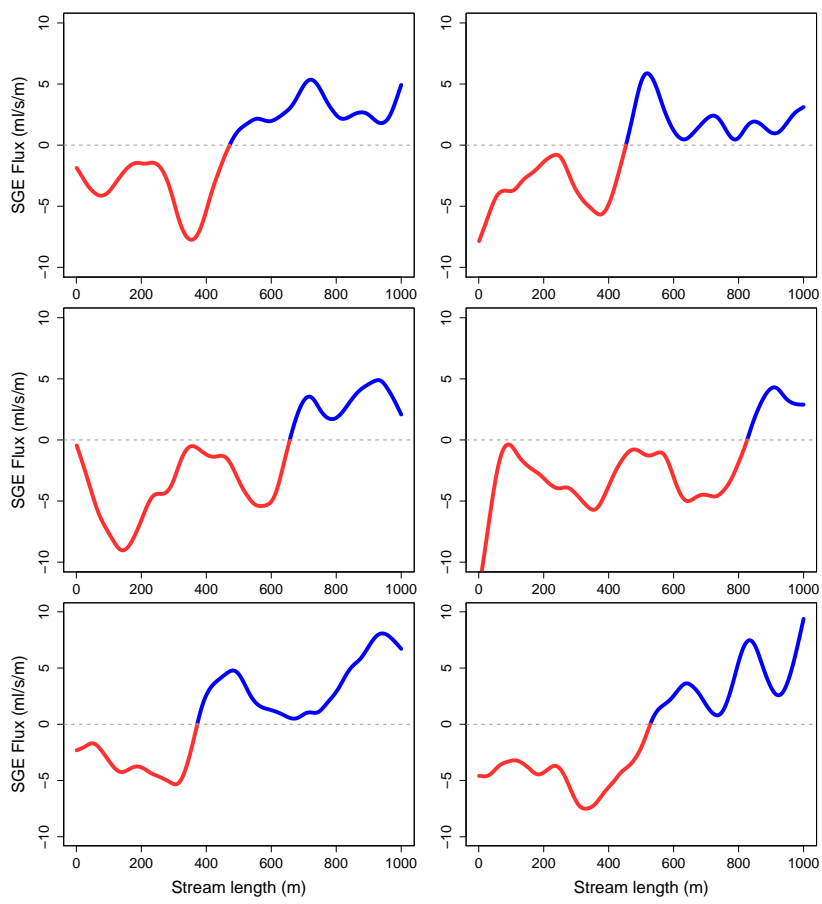

Figure 7. The simulated SGE profiles from series B (1000 m with $200 \mathrm{~m}$ average switch length) of the six scenarios with the smallest normalized error $\left(\varepsilon_{i}^{\mathrm{m}}\right)$ for $\mathrm{LG}(\mathrm{min})$. A clear pattern can be seen according to the spatial assumption of the method. Predominant stream losses are at the beginning, while stream gains are towards the end of the reach. Red indicates losses, while blue indicates gains.

ARIMA model. Although these circumstances may account for a small proportion of the total simulations, they can cause the average error to be very high. These large deviations are exemplified in the NRMSE measure due to the square of the difference. Net was clearly superior in series $\mathrm{C}$ and $\mathrm{D}$ for the $\bar{\varepsilon}^{\mathrm{m}}$ and for all series for the NRMSE, but GL (max) had a solid majority over Net in the $r_{\mathrm{m} 1, \mathrm{~m} 2}$. In series A, GL (max) and Net had a similar $\bar{\varepsilon}^{\mathrm{m}}$, but according to $r_{\mathrm{m} 1, \mathrm{~m} 2} \mathrm{GL}(\max )$ performed better almost $80 \%$ of the time. Indeed, if the top $10 \%$ of the simulations with the highest errors were removed from series C, then GL (max) and Net would have approximately the same $\bar{\varepsilon}^{\mathrm{m}}$. Nevertheless, even with the help of removing 10 or $20 \%$ of the simulations with the highest errors, both LG (min) and SIM perform substantially better than GL (max).

Since the LG ( $\min )$ and GL ( $\max )$ methods bound the realistic values of SGE, any new method must have spatial flux distribution assumptions that cause the SGE estimate to be in between LG (min) and GL (max). The SIM method has such assumptions. The ARIMA stream simulation model randomly generated stream flows with a specific reach length and switching length, and this was to evaluate the effects of both reach length and intermittency on the three SGE
Gain-Loss Series B
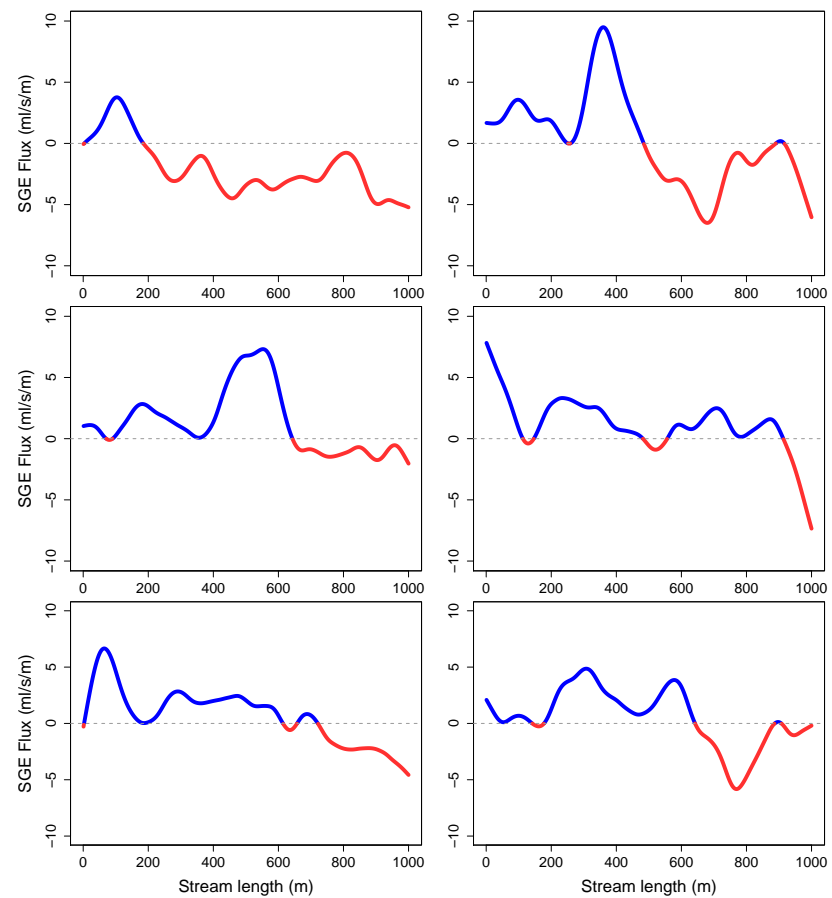

Figure 8. The simulated SGE profiles from series B (1000 m with $200 \mathrm{~m}$ average switch length) of the six scenarios with the smallest $\varepsilon_{i}^{\mathrm{m}}$ for GL (max). A clear pattern can be seen according to the spatial assumption of the method. Predominant stream gains are at the beginning, while stream losses are towards the end of the reach. Red indicates losses, while blue indicates gains.

methods. According to the $\bar{\varepsilon}^{\mathrm{m}}$ and the NRMSE, LG(min) and GL (max) were affected by both the switch length and the stream length. SIM was affected by stream length, but was not significantly affected by switch length. As LG (min) and GL (max) are affected by switch and stream length, the reader can extrapolate from Table 1 that as the stream length decreases and the switch length increases, the errors for LG (min) and GL (max) will continue to decrease, potentially below that of SIM.

No net emphasis on the $Q_{\text {gain }}$ or $Q_{\text {loss }}$ was programmed into the ARIMA model as shown by the normal distribution and mean of approximately 0 of $Q_{\text {net }}$ in Fig. 5. The introduction of a $Q_{\text {net }}$ emphasis towards a higher $Q_{\text {gain }}$ would cause the SGE estimates of $Q_{\text {loss }}$ of the three methods to slightly decrease or stay the same and the SGE estimates of $Q_{\text {gain }}$ to have significant improvement. An emphasis towards a higher $Q_{\text {loss }}$ would cause the SGE estimates of $Q_{\text {loss }}$ of the three methods to slightly improve or stay the same and the SGE estimates of $Q_{\text {gain }}$ to have a significant reduction in accuracy. Nevertheless, the accuracy rankings would remain the same as those listed in Table 1. If a weight was introduced into the ARIMA model on one type of spatial flux distribution, then the SGE model (i.e., LG (min) or GL $(\max )$ ) that 
Table 1. $\bar{\varepsilon}^{\mathrm{m}}$ : the average value of $\varepsilon_{i}^{\mathrm{m}}$ for each series and for both $Q_{\text {loss }}$ and $Q_{\text {gain }}$ (Corr. - correlation; Avg - average).

\begin{tabular}{|c|c|c|c|c|c|c|c|c|}
\hline \multirow[b]{2}{*}{ Series } & \multirow[b]{2}{*}{$\begin{array}{l}\text { Stream } \\
\text { length } \\
(\mathrm{m})\end{array}$} & \multirow[b]{2}{*}{$\begin{array}{l}\text { Avg switch } \\
\text { length }(\mathrm{m})\end{array}$} & \multirow[b]{2}{*}{$\begin{array}{l}\text { Corr. } \\
\text { length } \\
\text { (m) }\end{array}$} & \multirow[b]{2}{*}{ Flux type } & \multicolumn{4}{|c|}{ SGE method } \\
\hline & & & & & Net & $\mathrm{LG}(\min )$ & GL $(\max )$ & SIM \\
\hline \multirow{2}{*}{ A } & \multirow{2}{*}{1000} & \multirow{2}{*}{100} & \multirow{2}{*}{40} & $Q_{\text {loss }}$ & 0.821 & 0.243 & 0.675 & 0.115 \\
\hline & & & & $Q_{\text {gain }}$ & 0.821 & 0.264 & 0.849 & 0.135 \\
\hline \multirow{2}{*}{ B } & \multirow{2}{*}{1000} & \multirow{2}{*}{200} & \multirow{2}{*}{70} & $Q_{\text {loss }}$ & 0.775 & 0.183 & 0.421 & 0.111 \\
\hline & & & & $Q_{\text {gain }}$ & 0.763 & 0.204 & 0.591 & 0.143 \\
\hline \multirow{2}{*}{$\mathrm{C}$} & \multirow{2}{*}{2000} & \multirow{2}{*}{100} & \multirow{2}{*}{40} & $Q_{\text {loss }}$ & 0.852 & 0.393 & 2.390 & 0.170 \\
\hline & & & & $Q_{\text {gain }}$ & 0.855 & 0.422 & 2.949 & 0.194 \\
\hline \multirow{2}{*}{$\mathrm{D}$} & \multirow{2}{*}{2000} & \multirow{2}{*}{200} & \multirow{2}{*}{70} & $Q_{\text {loss }}$ & 0.815 & 0.306 & 1.268 & 0.168 \\
\hline & & & & $Q_{\text {gain }}$ & 0.821 & 0.339 & 1.652 & 0.202 \\
\hline
\end{tabular}

Table 2. NRMSE: the value of the NRMSE for each series and for both $Q_{\text {loss }}$ and $Q_{\text {gain }}$.

\begin{tabular}{|c|c|c|c|c|c|c|c|c|}
\hline \multirow[b]{2}{*}{ Series } & \multirow[b]{2}{*}{$\begin{array}{l}\text { Stream } \\
\text { length } \\
\text { (m) }\end{array}$} & \multirow[b]{2}{*}{$\begin{array}{l}\text { Avg switch } \\
\text { length }(\mathrm{m})\end{array}$} & \multirow[b]{2}{*}{$\begin{array}{l}\text { Corr. } \\
\text { length } \\
(\mathrm{m})\end{array}$} & \multirow[b]{2}{*}{ Flux type } & \multicolumn{4}{|c|}{ SGE method } \\
\hline & & & & & Net & $\mathrm{LG}(\min )$ & $\mathrm{GL}(\max )$ & SIM \\
\hline \multirow{2}{*}{ A } & \multirow{2}{*}{1000} & \multirow{2}{*}{100} & \multirow{2}{*}{40} & $Q_{\text {loss }}$ & 0.784 & 0.269 & 1.639 & 0.198 \\
\hline & & & & $Q_{\text {gain }}$ & 0.776 & 0.267 & 1.624 & 0.196 \\
\hline \multirow{2}{*}{ B } & \multirow{2}{*}{1000} & \multirow{2}{*}{200} & \multirow{2}{*}{70} & $Q_{\text {loss }}$ & 0.724 & 0.210 & 1.056 & 0.201 \\
\hline & & & & $Q_{\text {gain }}$ & 0.705 & 0.205 & 1.029 & 0.196 \\
\hline \multirow{2}{*}{$\mathrm{C}$} & \multirow{2}{*}{2000} & \multirow{2}{*}{100} & \multirow{2}{*}{40} & $Q_{\text {loss }}$ & 0.830 & 0.417 & 7.581 & 0.292 \\
\hline & & & & $Q_{\text {gain }}$ & 0.834 & 0.419 & 7.617 & 0.294 \\
\hline \multirow{2}{*}{$\mathrm{D}$} & \multirow{2}{*}{2000} & \multirow{2}{*}{200} & \multirow{2}{*}{70} & $Q_{\text {loss }}$ & 0.779 & 0.331 & 3.771 & 0.294 \\
\hline & & & & $Q_{\text {gain }}$ & 0.786 & 0.334 & 3.807 & 0.297 \\
\hline
\end{tabular}

most closely represented this weight would have a reduction in the error.

Most of the $\varepsilon_{i}^{\mathrm{m}}$ errors in LG (min) and GL (max) could be correlated by the ratio of the upstream and downstream concentrations for $Q_{\text {loss }}$ and the ratio of the upstream and downstream loads for $Q_{\text {gain }}$. $Q_{\text {loss,GL }}$ had an especially strong correlation. LG ( $\mathrm{min})$, however, had an especially strong correlation to the concentration and load midpoints along the stream (not shown in figures). As with much of the previous results, the midpoint correlations follow precisely the assumptions of the methods. LG (min) assumes that the $Q_{\text {loss }}$ occurs at the beginning and if the ratio of $C_{\text {mid }}$ to $C_{\text {up }}$ does not follow a relationship that the method assumes then it will produce a larger error. At least in LG (min), it appears that if the concentration ratio does not follow the predicted pattern by the time it reaches the midpoint, then the method is more likely to create erroneous results. A similar pattern can be seen in GL ( $\max$ ), but not nearly as strong as the upstream and downstream ratios. Unfortunately, SIM did not have such clear correlations. There only appears to be an error trend towards smaller upstream and downstream ratios.

There is much scientific literature on the estimation of SGE from chemical tracers. Many have preferred to use the well-established OTIS numerical model, which effectively solves the differential equations with a finite difference model with similar spatial flux assumptions to our SIM method. We found only one study that used the OTIS model and tested the three different assumptions that we also tested (Szeftel et al., 2011). However, the reasoning behind their test appeared to be precisely the opposite of ours. As they stated in the methods, they assumed that simultaneous inflows and outflows at a single cell was unrealistic and implemented the LG ( $\min$ ) and GL (max) type scenarios to provide more realistic alternatives. Although they did not test the accuracy of the three methods, they concluded that the spatial flux distribution assumptions of the SGE methods have a significant impact on the SGE estimates and that a breakthrough 


\section{Simultaneous Series B}
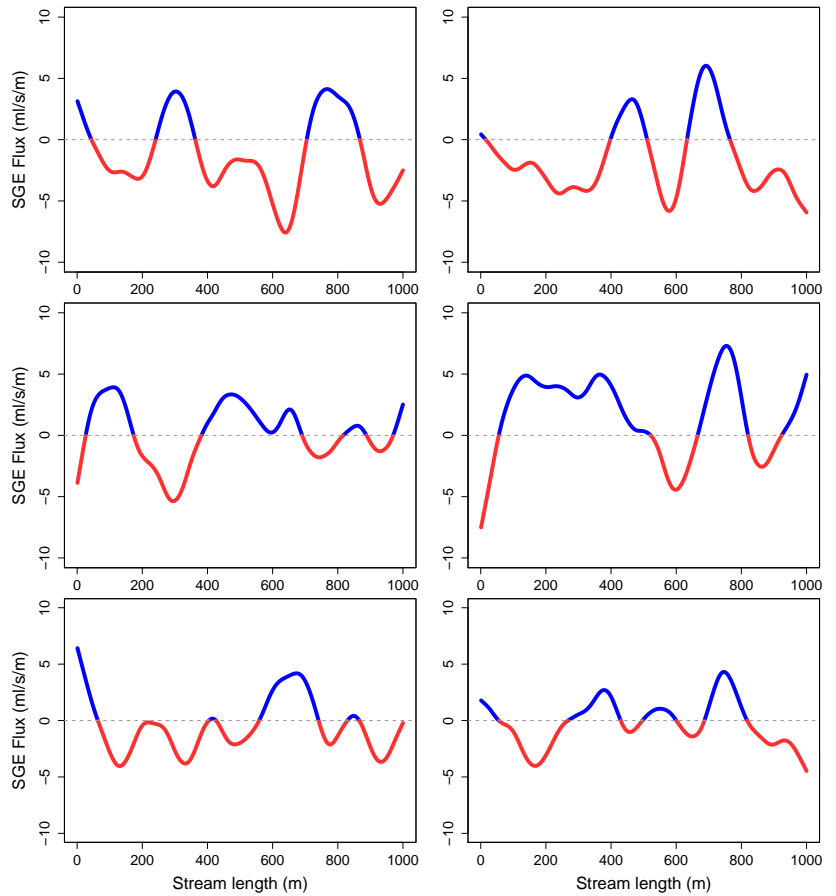

Figure 9. The simulated SGE profiles from series B (1000 m with $200 \mathrm{~m}$ average switch length) of the six scenarios with the smallest $\varepsilon_{i}^{\mathrm{m}}$ for SIM. No consistent or obvious pattern can be seen within the scenarios. Red indicates losses, while blue indicates gains.

curve (BTC) analysis is not sufficient to determine the spatial variability.

Like us, others have instead preferred to use the more simple analytical equations to estimate SGE (Harvey and Wagner, 2000; Payn et al., 2009; Covino et al., 2011). One of the earliest to hint at using tracers with analytical equations to determine SGE was Zellweger et al. (1989). The use of tracers with dilution gauging to estimate SGE was only mentioned in passing as an explanation for the differences in the estimation of discharge from a flow meter and from dilution gauging. Later, Harvey and Wagner (2000) picked up on the idea of using dilution gauging with a current meter to estimate SGE. Their description for the procedure to estimate SGE was purely qualitative and did not fully explain the underlying assumptions in the method that they proposed (i.e., the spatial distribution of the fluxes). The dilution gauging method to estimate discharge was referenced back to Kilpatrick and Cobb (1985). Based on the dilution gauging method and the description provided by Harvey and Wagner (2000), they effectively proposed the use of the GL (max) method. Payn et al. (2009) and Ward et al. (2013) estimated SGE using both the LG(min) and the GL ( $\max )$ methods. They also found significant differences in the estimations between the two different methods and correctly identified that the LG (min) and the GL (max) methods
Table 3. $r_{\mathrm{m} 1, \mathrm{~m} 2}$ : the ratios of the frequency that the methods in the rows (m1) have a smaller $\varepsilon_{i}^{\mathrm{m}}$ than the methods in the columns (m2). In simpler terms, the table shows how often the methods in the rows outperform the methods in the columns.

\begin{tabular}{|c|c|c|c|c|c|c|}
\hline & & & & Denomi & tor $(\mathrm{m} 2$ & \\
\hline & Series & Method & Net & $\begin{array}{l}\mathrm{LG} \\
(\min )\end{array}$ & $\begin{array}{l}\text { GL } \\
(\max )\end{array}$ & SIM \\
\hline & & Net & 0.000 & 0.000 & 0.204 & 0.014 \\
\hline & & LG (min) & 1.000 & 0.000 & 0.711 & 0.149 \\
\hline & A & GL (max) & 0.796 & 0.289 & 0.000 & 0.068 \\
\hline & & SIM & 0.985 & 0.851 & 0.931 & 0.000 \\
\hline & & Net & 0.000 & 0.000 & 0.143 & 0.022 \\
\hline & $\mathrm{B}$ & LG (min) & 1.000 & 0.000 & 0.627 & 0.223 \\
\hline$\Xi$ & B & GL (max) & 0.857 & 0.373 & 0.000 & 0.163 \\
\hline$\stackrel{\dot{0}}{0}$ & & SIM & 0.978 & 0.777 & 0.837 & 0.000 \\
\hline$\Xi$ & & Net & 0.000 & 0.000 & 0.501 & 0.029 \\
\hline & $C$ & LG (min) & 1.000 & 0.000 & 0.869 & 0.109 \\
\hline & C & GL (max) & 0.499 & 0.131 & 0.000 & 0.013 \\
\hline & & SIM & 0.971 & 0.891 & 0.987 & 0.000 \\
\hline & & Net & 0.000 & 0.000 & 0.352 & 0.037 \\
\hline & D & $\mathrm{LG}(\min )$ & 1.000 & 0.000 & 0.753 & 0.177 \\
\hline & D & GL (max) & 0.648 & 0.247 & 0.000 & 0.067 \\
\hline & & SIM & 0.963 & 0.823 & 0.933 & 0.000 \\
\hline
\end{tabular}

produce the minimum and maximum values for SGE, respectively. Similar studies were also performed in sewer systems (Rieckermann et al., 2005; Rieckermann et al., 2007). Although in these studies, the conceptual model included only $Q_{\text {loss }}$ and not $Q_{\text {gain }}$ and subsequently did not need to use a spatial distribution of fluxes assumption to solve for $Q_{\text {loss }}$.

\subsection{Connections with end-member mixing models}

End-member mixing models or end-member mixing analysis (EMMA) as they tend to be known is a method to estimate the relative contributions of defined source waters at a specific downstream discharge measurement point. For example, EMMA can estimate the amount of groundwater contribution within a single hydrograph. EMMA is used extensively for this precise purpose.

Similarly to the SGE methods, EMMA uses the mass balance equations with distinct chemical tracers that represent the end-member sources to formulate the model. The EMMA equations start with the assumption that the discharge at a specific point along the stream $(x)$ is composed of the source waters. We will name these sources source 1 (S1) and groundwater $(\mathrm{GW})$ :

$Q(x)=Q_{\mathrm{S} 1}(x)+Q_{\mathrm{GW}}(x)$, 

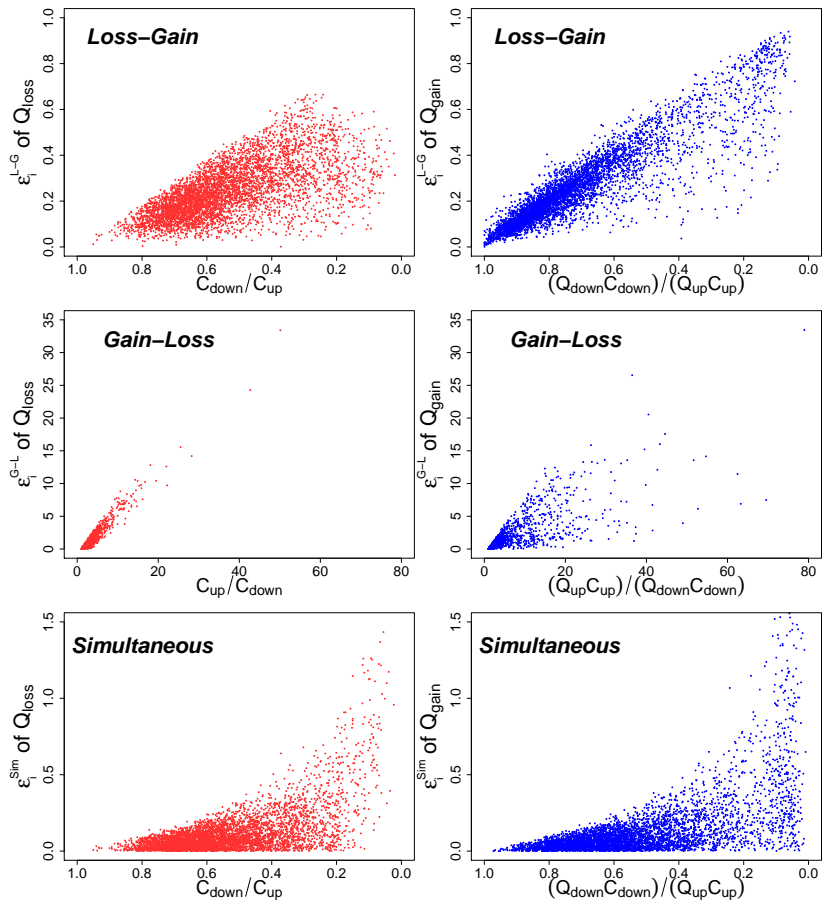

Figure 10. A correlation of various input parameters to $\varepsilon_{i}^{\mathrm{m}}$ of the SGE methods for series A. Both the LG (min) and GL (max) methods have strong correlations, while SIM only tends to have an error trend at lower ratios.

where $Q(x)$ is the total discharge at location $x$ along the stream, $Q_{\mathrm{S} 1}(x)$ is the part of $Q(x)$ from source 1, and $Q_{\mathrm{GW}}(x)$ is the part of $Q(x)$ from groundwater. The chemical load mass balance is the following:

$Q(x) C(x)=Q_{\mathrm{S} 1}(x) C_{\mathrm{S} 1}+Q_{\mathrm{GW}}(x) C_{\mathrm{GW}}$,

where $C(x)$ is the concentration of $Q(x)$ at location $x, C_{\mathrm{S} 1}$ is the concentration of source 1 , and $C_{\mathrm{GW}}$ is the concentration of the groundwater.

Unlike the SGE methods that apply the mass balance equations over the length of a stream reach, the EMMA equations only apply the mass balance equations at one specific point and as a result do not need the same spatial flux assumptions to solve the mass balance equations as the SGE methods (i.e., do not require a $Q_{\text {loss }}$ term).

Combining Eqs. (35) and (36) and solving for $Q_{\mathrm{GW}}(x)$, we get the following:

$Q_{\mathrm{GW}}(x)=Q(x)\left(\frac{C(x)-C_{\mathrm{S} 1}}{C_{\mathrm{GW}}-C_{\mathrm{S} 1}}\right)$.

Equation (37) will produce the same result regardless of the spatial flux assumptions associated with the SGE methods presented in this study.

Equation (37) is strikingly similar to Eq. (5). Indeed, if we apply the LG $(\mathrm{min})$ method at an arbitrary discharge location $(x)$ and use $C_{\text {up }}$ as $C_{\mathrm{S} 1}$, then we would produce the

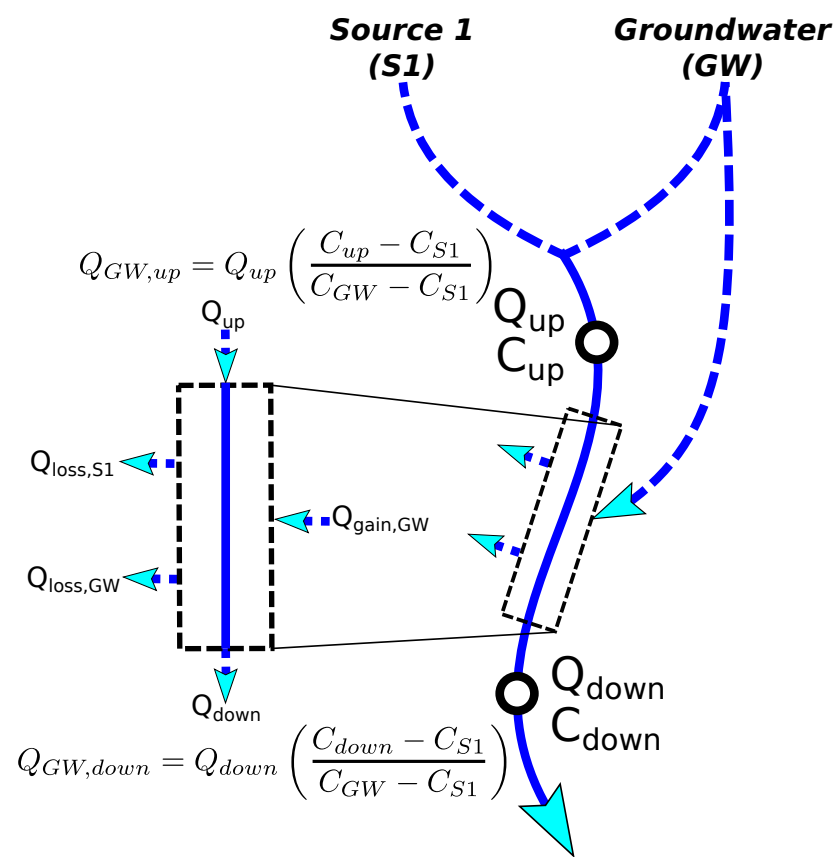

Figure 11. A conceptual illustration of the application of EMMA at two measurement locations along a stream reach and the associated gross gain and loss components between the two measurement locations. $Q_{\mathrm{GW} \text {,up }}$ is the groundwater proportion of $Q_{\mathrm{up}}$ and $Q_{\mathrm{GW}, \text { down }}$ is the groundwater proportion of $Q_{\mathrm{down}} \cdot Q_{\text {loss,S1 }}$ is the gross loss specifically from source $1, Q_{\text {loss, GW }}$ is the gross loss specifically from the groundwater, and $Q_{\text {gain,GW }}$ is the gross gain from the groundwater (and the only gross gain). The SGE methods estimate the total gross loss $\left(Q_{\text {loss, } \mathrm{S} 1}+Q_{\text {loss, GW }}\right)$ and gross gain $\left(Q_{\text {gain,GW }}\right)$. Subtracting $Q_{\mathrm{GW} \text {,up }}$ from $Q_{\mathrm{GW} \text {,down }}$ estimates $Q_{\text {loss,S1 }}$ and the net of the groundwater components ( $\left.Q_{\text {gain, GW }}-Q_{\text {loss,GW }}\right)$.

same result for both EMMA and SGE (if we want to make the LG(min) spatial assumption). As described above, this is not due to shared assumptions. The LG ( $\min$ ) method assumes that all of the $Q_{\text {gain }}$ enters the stream after the $Q_{\text {loss }}$ and thus the $Q_{\text {gain }}$ estimated by the LG(min) method must be the groundwater proportion of $Q_{\text {down }}$.

If EMMA can be applied to a single stream measurement location and produce the same results as the LG (min) SGE method, the next natural question would be whether EMMA could be applied on multiple downstream measurement locations and still produce the same results as LG ( $\mathrm{min})$. If we estimate the groundwater proportions at two downstream measurement locations using EMMA, could we subtract the two to get the estimated gross gain of groundwater over that stream reach? Figure 11 illustrates the use of EMMA for estimating the groundwater proportions of the upstream $\left(Q_{\mathrm{GW}, \text { up }}\right)$ and downstream $\left(Q_{\mathrm{GW} \text {,down }}\right)$ measurement locations and the gross gains and losses from the two sources. In this scenario, we want to consider if 
$Q_{\text {gain,EMMA }}=Q_{\mathrm{GW}, \text { down }}-Q_{\mathrm{GW} \text {,up. }}$ Using Eq. (37) at $Q_{\text {up }}$ and $Q_{\text {down }}$, we get the following:

$Q_{\text {gain,EMMA }}=Q_{\text {down }}\left(\frac{C_{\text {down }}-C_{\mathrm{S} 1}}{C_{\mathrm{GW}}-C_{\mathrm{S} 1}}\right)-Q_{\mathrm{up}}\left(\frac{C_{\mathrm{up}}-C_{\mathrm{S} 1}}{C_{\mathrm{GW}}-C_{\mathrm{S} 1}}\right)$

where $Q_{\text {gain,EMMA }}$ is the hypothetical $Q_{\text {gain }}$ from the EMMA equations. To determine the underlying assumptions in the above equation, we must rearrange the equation back to the basic mass balance equation from Eq. (1) including both Eq. (38) and Eq. (2).

$Q_{\mathrm{up}} C_{\mathrm{up}}+Q_{\text {gain,EMMA }} C_{\mathrm{GW}}=Q_{\mathrm{down}} C_{\mathrm{down}}+Q_{\text {loss }} C_{\mathrm{S} 1}$

As stated in Sect. 2.1, the LG(min) method assumes $C_{\text {loss }}=C_{\text {up }}$ and the GL (max) method assumes $C_{\text {loss }}=C_{\text {down }}$. $C_{\text {up }}$ and $C_{\text {down }}$ represent the end point concentrations within the stream and thus LG ( $\min$ ) and GL (max) represent the realistic minimum and maximum values for SGE. The use of EMMA according to Eq. (38) makes the final assumption of $C_{\text {loss }}=C_{\mathrm{S} 1}$ and represents a concentration end point potentially outside of $C_{\text {up }}$ and $C_{\text {down }}$, which indicates that this is an unrealistic mass balance assumption for SGE models.

For the mass balance Eq. (39) to have physical meaning, we would have to redefine $Q_{\text {gain,EMMA }}$ and $Q_{\text {loss }} . Q_{\text {loss }}$ would no longer be the gross loss from the SGE methods, but rather only the loss from source 1 over the stream reach (we will rename $Q_{\text {loss,S1 }}$ ). The other gross loss component is from the groundwater $\left(Q_{\text {loss,GW }}\right)$. $Q_{\text {gain,EMMA }}$ would become the net groundwater components instead of only $Q_{\text {gain,GW }}$ (i.e., $Q_{\text {gain,GW }}-Q_{\text {loss, GW }}$ ). These flow components are shown in Fig. 11. Consequently, Eq. (39) can be rewritten with $Q_{\text {loss }}$ replaced as $Q_{\text {loss,S1 }}$ and $Q_{\text {gain,EMMA }}$ replaced with the appropriate net groundwater components:

$$
\begin{array}{r}
Q_{\mathrm{up}} C_{\mathrm{up}}+\left(Q_{\mathrm{gain}, \mathrm{GW}}-Q_{\text {loss, GW }}\right) C_{\mathrm{GW}} \\
=Q_{\mathrm{down}} C_{\mathrm{down}}+Q_{\text {loss }, \mathrm{S} 1} C_{\mathrm{S} 1} .
\end{array}
$$

Equation (40) is the solute mass balance for this scenario. The water mass balance would be the following (in the same form as Eq. 2):

$$
Q_{\text {up }}+Q_{\text {gain }, \mathrm{GW}}=Q_{\text {down }}+Q_{\text {loss }, \mathrm{GW}}+Q_{\text {loss }, \mathrm{S} 1} .
$$

If we combine Eqs. (40) and (41) and solve for $Q_{\text {loss,S1, we }}$ get the following equation:

$Q_{\text {loss }, \mathrm{S} 1}=\frac{Q_{\text {down }}\left(C_{\mathrm{down}}-C_{\mathrm{GW}}\right)+Q_{\mathrm{up}}\left(C_{\mathrm{GW}}-C_{\mathrm{up}}\right)}{C_{\mathrm{GW}}-C_{\mathrm{S} 1}}$.

The interesting aspect about Eq. (42) is that no spatial flux assumption is yet needed to solve the derivation unlike with the SGE methods. $Q_{\text {loss,S1 }}$ is independent of spatial flux assumptions and so is the result from Eq. (38) which represents $Q_{\text {gain,GW }}-Q_{\text {loss,GW }}$. Although both $Q_{\text {gain,GW }}$ and

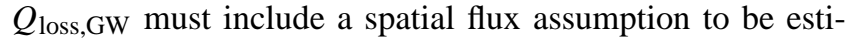
mated individually, the difference will always be the same regardless of the spatial flux assumption. In this scenario, $Q_{\text {gain,GW }}$ can be estimated using the SGE methods described in Sect. 2 and subsequently the components of $Q_{\text {loss. }}$. The additional information about source 1 provides slightly more information about $Q_{\text {loss }}$ without the necessity of a spatial flux assumption.

To take the EMMA and SGE combination to the final logical conclusion, we will include a scenario where there are two component inflows and outflows unlike the previous example with one inflow and two outflows. We will call the two sources "source 1" and "source 2" with variable names similar to those presented above. The mass balance for $Q_{\text {gain }}$ for a stream reach is the following:

$Q_{\text {gain }}=Q_{\text {gain, }, \mathrm{S} 1}+Q_{\text {gain, } \mathrm{S} 1}$

and

$Q_{\text {gain }} C_{\text {gain }}=Q_{\text {gain,S1 }} C_{\mathrm{S} 1}+Q_{\text {gain }, \mathrm{S} 2} C_{\mathrm{S} 2}$

If we combine Eqs. (43) and (44) and solve for $Q_{\text {gain,S1, we }}$ get the following equation:

$Q_{\text {gain,S1 }}=Q_{\text {gain }}\left(\frac{C_{\text {gain }}-C_{\mathrm{S} 2}}{C_{\mathrm{S} 1}-C_{\mathrm{S} 2}}\right)$.

To estimate $Q_{\text {loss,S1 }}$, we need to incorporate $Q_{\text {gain,S1 }}$ into Eqs. (40) and (41) and change the groundwater terms to source 2. Combining the resulting equation and solving for $Q_{\text {loss,S1 }}$ gives the following:

$Q_{\text {loss }, \mathrm{S} 1}=\left(\frac{Q_{\mathrm{up}}\left(C_{\mathrm{up}}-C_{\mathrm{S} 2}\right)+Q_{\mathrm{down}}\left(C_{\mathrm{S} 2}-C_{\mathrm{down}}\right)}{C_{\mathrm{S} 2}-C_{\mathrm{S} 1}}\right)-Q_{\mathrm{gain}, \mathrm{S} 1}$.

Combining EMMA with SGE methods can provide valuable complimentary hydrologic information. They both require the same type of input data and as a consequence would be easy to apply together. They should not, however, be used interchangeably due to both conceptual and quantitative conflicts.

\section{Conclusions}

A new SGE estimation method is presented and derived analytically with the assumptions of constant, uniform, and simultaneous groundwater inflow and outflow throughout a given stream reach. This new method is compared to the two existing methods and presents the smallest error measures when applied to four different sets of artificially generated scenarios. The main control of the model performance for all three cases is the spatial dynamics of the actual SGE in relationship with the assumptions for each method. As the LG (min) and GL (max) methods bound the realistic values of SGE estimates, the SIM method, or any other new SGE method, produces SGE estimates between those two methods. Although this study found that the SIM method performed better against the numerical simulations, estimating 
SGE using all three methods would be very valuable as minimum and maximum SGE values can provide information on the full range of realistic SGE values. For the same inputs, the different assumptions of each method can lead to values of gross stream gains and losses differing up to one order of magnitude between approaches. Estimating SGE using the proposed simple analytical method over numerical models solving full hydrodynamic sets of partial differential equations has the clear advantages of much less complexity and less parametrization.
Although separate from the SGE methods, end-member mixing analysis can be used in conjunction with the SGE methods to acquire even more hydrologic information as both require the same type of input data. Nevertheless, these two approaches should not be used interchangeably as they estimate different stream variables and are based on distinct derivations and assumptions. 


\section{Appendix A: Derivation of the inflowing groundwater concentration $\left(C_{\text {gain }}\right)$ from stream tracer tests}

The derivation of $C_{\text {gain }}$, the tracer concentration of the inflowing groundwater, is different than that of the SGE equations. The derivation of $C_{\text {gain }}$ is actually more similar to the initial derivation from the conceptual model starting from Eq. (40) in Sect. 4.2. Figure 11 represents this conceptual model quite well. The exception to Fig. 11 is that for the derivation of $C_{\text {gain }}$ we are not interested in end members above $Q_{\text {up }}$. Consequently, the location of $Q_{\text {up }}$ becomes the upper end member and the mass balance for total $Q_{\text {loss }}$ becomes

$Q_{\text {loss }}=Q_{\text {loss,up }}+Q_{\text {loss }, \mathrm{GW}}$

and

$Q_{\text {loss }} C_{\text {loss }}=Q_{\text {loss }, \mathrm{up}} C_{\mathrm{up}}+Q_{\text {loss, } \mathrm{GW}} C_{\text {gain }}$,

where $Q_{\text {loss,up }}$ is the loss of water from the stream reach specifically from the original upstream water, $Q_{\text {loss, GW }}$ is the loss of water from the stream reach specifically from the inflowing groundwater, and $C_{\text {gain }}$ is the groundwater concentration of the tracer (denoted $C_{\mathrm{GW}}$ in Sect. 4.2).

As we are only interested in $C_{\text {gain }}$ and not the gross gains and losses for this derivation, we can collect the gross groundwater terms together as net groundwater similarly to Eq. (40). We get the following mass balance equations by including Eq. (A2) with Eq. (1) and Eq. (A1) with Eq. (2):

$$
\begin{gathered}
Q_{\text {up }} C_{\text {up }}+\left(Q_{\text {gain, GW }}-Q_{\text {loss, GW }}\right) C_{\text {gain }} \\
=Q_{\text {down }} C_{\text {down }}+Q_{\text {loss,up }} C_{\text {up }}
\end{gathered}
$$

and

$$
Q_{\text {gain, }, \mathrm{WW}}-Q_{\text {loss, } \mathrm{GW}}=Q_{\text {down }}-Q_{\text {up }}+Q_{\text {loss,up }} .
$$

With these two equations alone, we cannot solve for $C_{\text {gain }}$ as we still have too many unknown variables. A stream tracer test with a conservative tracer (e.g., chloride salt) will provide us with the additional equation. As described in the paragraph prior to Eq. (26), the required assumptions are $Q_{\text {gain,GW }}>0$ and that quasi-steady-state conditions apply before and after the tracer injection when the water samples are taken. By measuring the tracer concentrations before and after the tracer injection, we can form two distinct equations from Eq. (A3):

$$
\begin{aligned}
& Q_{\text {up }} C_{\text {up,prior }}+\left(Q_{\text {gain, GW }}-Q_{\text {loss,GW }}\right) C_{\text {gain }} \\
& =Q_{\text {down }} C_{\text {down,prior }}+Q_{\text {loss,up }} C_{\text {up,prior }} \text {, } \\
& Q_{\text {up }} C_{\text {up,post }}+\left(Q_{\text {gain, GW }}-Q_{\text {loss, GW }}\right) C_{\text {gain }} \\
& =Q_{\text {down }} C_{\text {down,post }}+Q_{\text {loss,up }} C_{\text {up,post }} \text {, }
\end{aligned}
$$

where the notation of the before and after tracer injection concentrations is the same to that of Eq. (27). Combining Eqs. (A4), (A5), and (A6) and solving for $C_{\text {gain }}$, we get the final result:

$C_{\text {gain }}=\frac{C_{\text {up,prior }} C_{\text {down,post }}-C_{\text {down,prior }} C_{\text {up,post }}}{C_{\text {up,prior }}-C_{\text {up,post }}-C_{\text {down,prior }}+C_{\text {down,post }}}$.

As mentioned earlier in this appendix section, Eq. (A7) does not require a spatial distribution assumption to derive the equation and consequently can be applied with any of the SGE methods listed in this manuscript.

To solve for $C_{\text {gain }}$, we took one stream reach with two different states in time. These two states of the same stream reach allowed creating two equations from Eq. (A2), because several concentration variables changed significantly due to the tracer injection. Instead of taking the same stream reach at different time states, we can also take two adjacent stream reaches under the same time state to create two equations from Eq. (A2) if we can assume that the two adjacent stream reaches have the same $C_{\text {gain }}$. Each of the two adjacent stream reaches would have an equation and the derivation would be similar to that for Eq. (A7). Although this is possible conceptually and mathematically, in practice the result may prove to be highly uncertain as the differences in the concentration values in the adjacent reaches may be very similar. This is the advantage of the tracer injection procedure described above. The larger the difference between the background concentration of the tracer in the stream and the tracer concentration in the stream due to the tracer injection will increase the accuracy of the estimate of $C_{\text {gain }}$. 
Appendix B: Additional methods associated with the SGE methods

Although the following methods were not used directly in this study, they can provide useful complementary information for SGE studies.

There might be a need to estimate the groundwater concentration of other chemical solutes entering the stream in addition to the conservative tracer used to estimate the SGE. If other in-stream gains and losses in the new chemical solute can be neglected (e.g., without biochemical transformations), the only additional information needed would be the concentration of the new compound at the locations of $Q_{\text {up }}$ and $Q_{\text {down }}$. The $C_{\text {gain }}$ of the new chemical solute can be estimated using the following rearrangement of Eq. (21):

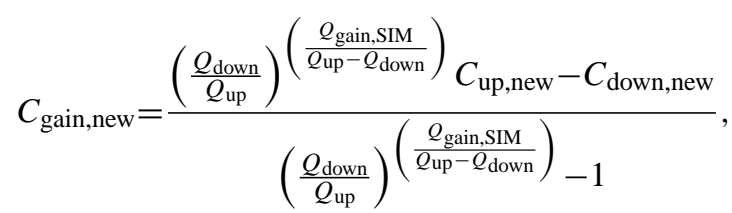

where $C_{\text {gain,new }}$ is the concentration of the new solute entering the stream from the groundwater, $C_{\text {up,new }}$ is the upstream concentration of the new solute, and $C_{\text {down,new }}$ is the downstream concentration of the new solute. Any of the three SGE methods can be rearranged to calculate $C_{\text {gain,new }}$ and they will all produce the same result.

Following on the same spatial flow distribution assumption as the SIM method, an additional mass removal rate can be integrated to potentially represent a relevant physical, chemical, or biological process (e.g., ammonia removal by microorganisms). The assumptions are simultaneous and uniform losses throughout the stream reach and stationary in time. The derivation would require a mass removal term per unit stream length $n_{\text {rem }}$ to be added to the right side of Eq. (14):

$\dot{m}(x)+C_{\text {gain }} q_{\text {gain }} \mathrm{d} x=\left(\dot{m}(x)+\frac{\partial \dot{m}(x)}{\partial x} \mathrm{~d} x\right)+C(x) q_{\text {loss }} \mathrm{d} x+n_{\text {rem }} \mathrm{d} x$.
The derivation would follow similarly to that of the SIM method derivation, and the final result solving for $Q_{\text {gain }}$ is the following:

$Q_{\text {gain }, \text { SIM }}=\left(Q_{\text {up }}-Q_{\text {down }}\right) \frac{\ln \left[\frac{C_{\text {down }}-C_{\text {gain }}-\frac{N_{\text {rem }}}{Q_{\text {gain }, \text { IIM }}}}{C_{\text {up }}-C_{\text {gain }}-\frac{N_{\text {rem }}}{Q_{\text {gain,SIM }}}}\right]}{\ln \left[\frac{Q_{\text {down }}}{Q_{\text {up }}}\right]}$,

where $N_{\text {rem }}$ is the total mass removal (mass per time) within the stream reach, and $C_{\text {up }}, C_{\text {down }}$, and $C_{\text {gain }}$ in this case would be solute concentrations associated with $N_{\text {rem }}$ (i.e., ammonia concentrations for ammonia mass removal). Solving for $N_{\text {rem }}$, we get the following:

$N_{\text {rem }}=\frac{Q_{\text {gain }, \text { SIM }}}{1-D_{\text {dis }}}\left[D_{\text {dis }}\left(C_{\text {up }}-C_{\text {gain }}\right)-C_{\text {down }}+C_{\text {gain }}\right]$

with

$D_{\text {dis }}=e^{\frac{Q_{\text {gain }, \text { SIM }}}{Q_{\text {up }}-Q_{\text {down }}} \ln \left[\frac{Q_{\text {down }}}{Q_{\text {up }}}\right]}$.

$Q_{\text {gain,SIM }}$ would need to be estimated from Eq. (21) using a conservative tracer. $C_{\text {gain }}$ could again be estimated using Eq. (B1) if we can safely assume that mass removal rates do not change over time before and after the tracer injection of the new solute. The key assumption limitation in this conceptual model is that over the short period of time of the solute tracer application the removal rate is not dependent on changes in concentration, which is certainly not true for many processes over long periods of time and also may not be true over short periods of time for certain processes. Although other mass removal models may provide a more realistic assumption in many cases (e.g., Michaelis-Menten kinetics, first order removal, etc.), $C_{\text {gain }}$ could not be estimated from Eq. (B1) using other more complicated assumptions and furthermore would require more measurements and/or parameter estimation techniques to include the additional necessary terms (Workshop, 1990). A thorough analysis on the analytical derivations of solute dynamics in stream ecosystems including first-order and nonlinear removal can be found in Workshop (1990). 
Acknowledgements. We would like to thank the Austrian Science Foundation for funding our work as part of the Vienna Doctoral Programme on Water Resource Systems (DK Plus W1219-N22). We would also like to thank both Günter Blöschl and Ranvir Singh for their helpful discussions and feedback. We would also like to thank the editor, Brian McGlynn, and the anonymous reviewers for their valuable feedback.

Edited by: B. McGlynn

\section{References}

Anderson, J. K., Wondzell, S. M., Gooseff, M. N., and Haggerty, R.: Patterns in stream longitudinal profiles and implications for hyporheic exchange flow at the H. J. Andrews Experimental Forest, Oregon, USA, Hydrol. Process., 19, 2931-2949, doi:10.1002/hyp.5791, 2005.

Arfken, G. B. and Weber, H.-J.: Mathematical methods for physicists, Elsevier, Boston, 2005.

Blöschl, G. and Sivapalan, M.: Scale issues in hydrological modelling: A review, Hydrol. Process., 9, 251-290, doi:10.1002/hyp.3360090305, 1995.

Briggs, M. A., Lautz, L. K., and McKenzie, J. M.: A comparison of fibre-optic distributed temperature sensing to traditional methods of evaluating groundwater inflow to streams, Hydrol. Process., 26, 1277-1290, doi:10.1002/hyp.8200, 2012.

Castro, N. M. and Hornberger, G. M.: Surface-subsurface water interactions in an alluviated mountain stream channel, Water Resour. Res., 27, 1613-1621, 1991.

Covino, T., McGlynn, B., and Mallard, J.: Stream-groundwater exchange and hydrologic turnover at the network scale, Water Resour. Res., 47, W12512, doi:10.1029/2011WR010942, 2011.

Harvey, J. and Bencala, K.: The effect of streambed topography on surface-subsurface water exchange in mountain catchments, Water Resour. Res., 29, 89-98, 1993.

Harvey, J. and Wagner, B.: Quantifying Hydrologic Interactions between Streams and Their Subsurface Hyporheic Zones, Elsevier, San Diego, California, USA, 3-44, doi:10.1016/b978012389845-6/50002-8, 2000.

Kalbus, E., Reinstorf, F., and Schirmer, M.: Measuring methods for groundwater - surface water interactions: a review, Hydrol. Earth Syst. Sci., 10, 873-887, doi:10.5194/hess-10-873-2006, 2006.

Kilpatrick, F. A. and Cobb, E. D.: Measurement of discharge using tracers, no. 3 in US Geological Survey Techniques of WaterResources Investigations, Department of the Interior, US Geological Survey, United States Government Printing Office, Washington, 1985.

Lowry, C. S., Walker, J. F., Hunt, R. J., and Anderson, M. P.: Identifying spatial variability of groundwater discharge in a wetland stream using a distributed temperature sensor, Water Resour. Res., 43, W10408, doi:10.1029/2007WR006145, 2007.

Malard, F., Tockner, K., Dole-Olivier, M.-J., and Ward, J. V.: A landscape perspective of surface-subsurface hydrological exchanges in river corridors, Freshwater Biol., 47, 621-640, 2002.

Mwakanyamale, K., Slater, L., Day-Lewis, F., Elwaseif, M., and Johnson, C.: Spatially variable stage-driven groundwater-surface water interaction inferred from time-frequency analysis of distributed temperature sensing data, Geophys. Res. Lett., 39, L06401, doi:10.1029/2011GL050824, 2012.
Payn, R. A., Gooseff, M. N., Benson, D. A., Cirpka, O. A., Zarnetske, J. P., Bowden, W. B., McNamara, J. P., and Bradford, J. H.: Comparison of instantaneous and constant-rate stream tracer experiments through non-parametric analysis of residence time distributions, Water Resour. Res., 44, W06404, doi:10.1029/2007WR006274, 2008.

Payn, R. A., Gooseff, M. N., McGlynn, B. L., Bencala, K. E., and Wondzell, S. M.: Channel water balance and exchange with subsurface flow along a mountain headwater stream in Montana, United States, Water Resour. Res., 45, W11427, doi:10.1029/2008WR007644, 2009.

R Development Core Team: R: A Language and Environment for Statistical Computing, http://www.R-project.org/ (last access: 20 June 2013), 2011.

Rieckermann, J., Borsuk, M., Reichert, P., and Gujer, W.: A novel tracer method for estimating sewer exfiltration, Water Resour. Res., 41, W05013, doi:10.1029/2004WR003699, 2005.

Rieckermann, J., Bare, V., Kracht, O., Braun, D., and Gujer, W.: Estimating sewer leakage from continuous tracer experiments, Water Res., 41, 1960-1972, doi:10.1016/j.watres.2007.01.024, 2007.

Ruehl, C., Fisher, A., Hatch, C., Huertos, M. L., Stemler, G., and Shennan, C.: Differential gauging and tracer tests resolve seepage fluxes in a strongly-losing stream, J. Hydrol., 330, 235-248, doi:10.1016/j.jhydrol.2006.03.025, 2006.

Runkel, R. L.: One-dimensional transport with inflow and storage (OTIS): A solute transport model for streams and rivers, US Department of the Interior, US Geological Survey, http: //webarchive.nced.umn.edu/system/files/runkel1998.pdf (last access: 15 June 2014), 1998.

Scanlon, B. R., Healy, R. W., and Cook, P. G.: Choosing appropriate techniques for quantifying groundwater recharge, Hydrogeol. J., 10, 347-347, doi:10.1007/s10040-002-0200-1, 2002.

Schmidt, C., Bayer-Raich, M., and Schirmer, M.: Characterization of spatial heterogeneity of groundwater-stream water interactions using multiple depth streambed temperature measurements at the reach scale, Hydrol. Earth Syst. Sci., 10, 849-859, doi:10.5194/hess-10-849-2006, 2006.

Slater, L. D., Ntarlagiannis, D., Day-Lewis, F. D., Mwakanyamale, K., Versteeg, R. J., Ward, A., Strickland, C., Johnson, C. D., and Lane, J. W.: Use of electrical imaging and distributed temperature sensing methods to characterize surface waterroundwater exchange regulating uranium transport at the Hanford 300 Area, Washington, Water Resour. Res., 46, W10533, doi:10.1029/2010WR009110, 2010.

Szeftel, P., (Dan) Moore, R., and Weiler, M.: Influence of distributed flow losses and gains on the estimation of transient storage parameters from stream tracer experiments, J. Hydrol., 396, 277291, doi:10.1016/j.jhydrol.2010.11.018, 2011.

Wagner, B. J. and Harvey, J. W.: Experimental design for estimating parameters of rate-limited mass transfer: Analysis of stream tracer studies, Water Resour. Res., 33, 1731-1741, doi:10.1029/97WR01067, 1997.

Ward, A. S., Payn, R. A., Gooseff, M. N., McGlynn, B. L., Bencala, K. E., Kelleher, C. A., Wondzell, S. M., and Wagener, T.: Variations in surface water - ground water interactions along a headwater mountain stream: Comparisons between transient storage and water balance analyses, Water Resour. Res., 49, 3359-3374, doi:10.1002/wrcr.20148, 2013. 
Westhoff, M. C., Savenije, H. H. G., Luxemburg, W. M. J ., Stelling, G. S., van de Giesen, N. C., Selker, J. S., Pfister, L., and Uhlenbrook, S.: A distributed stream temperature model using high resolution temperature observations, Hydrol. Earth Syst. Sci., 11, 1469-1480, doi:10.5194/hess-11-1469-2007, 2007.

Winter, T. C.: Ground water and surface water: a single resource, no. 1139 in US Geological Survey circular, US Geological Survey, Denver, Colorado, 1998.

Wondzell, S. M.: Effect of morphology and discharge on hyporheic exchange flows in two small streams in the Cascade Mountains of Oregon, USA, Hydrol. Process., 20, 267-287, 2005.
Workshop, S. S.: Concepts and Methods for Assessing Solute Dynamics in Stream Ecosystems, J. N. Am. Benthol. Soc., 9, 95119, doi:10.2307/1467445, 1990.

Zellweger, G. W., Avanzino, R. J., and Bencala, K. E.: Comparison of tracer-dilution and current-meter discharge measurements in a small gravel-bed stream, Little Lost Man Creek, California, Department of the Interior, US Geological Survey, Menlo Park, California, 1989. 